\title{
Ecosystem service trade-offs and their influencing factors: A case study in the Loess Plateau of China
}

\author{
Qiang Feng ${ }^{\mathrm{a}, \mathrm{c}}$, Wenwu Zhao ${ }^{\mathrm{a}, *}$, Bojie Fu ${ }^{\mathrm{a}, \mathrm{b}}$, Jingyi Ding ${ }^{\mathrm{a}}$, Shuai Wang ${ }^{\mathrm{a}}$ \\ a State Key Laboratory of Earth Surface Processes and Resource Ecology, Faculty of Geographical Science, Beijing Normal University, Beijing 100875, PR China \\ b State Key Laboratory of Urban and Regional Ecology, Research Center for Eco-Environmental Sciences, Chinese Academy of Sciences, P.O. Box 2871, Beijing 100085, PR China \\ c College of Forestry, Shanxi Agricultural University, Taigu, Shanxi 030801, PR China
}

\section{H I G H L I G H T S}

- Three ESs are assessed based on field experiments.

- The ESs trade-offs are quantified and redundancy analysis is used.

- The environmental factors interact and they have complex influence on tradeoffs.

- The dominant factors for trade-offs are revealed and revegetation advice is proposed.

\section{A R T I C L E I N F O}

\section{Article history:}

Received 19 May 2017

Received in revised form 9 July 2017

Accepted 10 July 2017

Available online 17 July 2017

\section{Keywords:}

Ecosystem services relationship

Soil erosion control

Carbon sequestration

Soil moisture

Environmental factors
GRAPHICALA B S T R C T

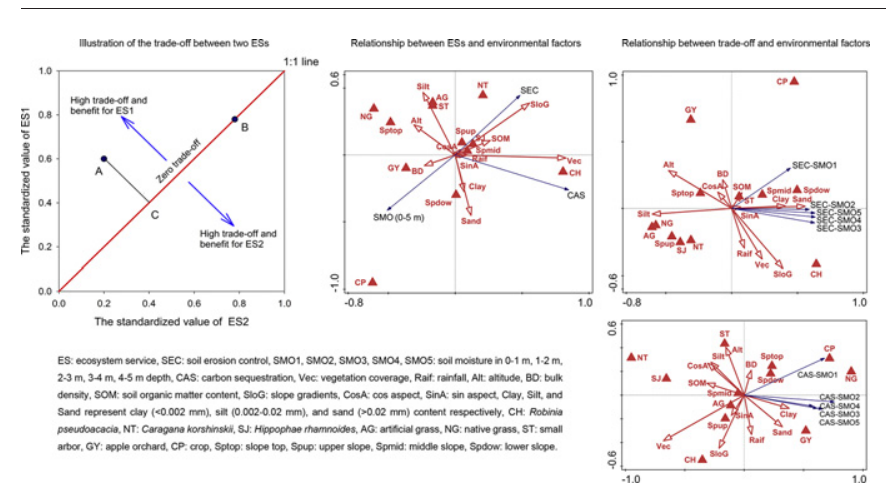

\begin{abstract}
A B S T R A C T
Soil erosion control (SEC), carbon sequestration (CAS), and soil moisture (SMO) strongly interact in the semi-arid Loess Plateau. Since SMO has supportive effects on SEC and CAS, it can be considered as ecosystem service (ES), and there is an immediate need to coordinate the relationships among these ecosystem services (ESs) to promote the sustainability of vegetation recovery. In this study, we quantified the ESs, ES trade-offs, and the environmental factors in 151 sample plots in the Ansai watershed, and we used a redundancy analysis (RDA) to clarify the effects of environmental factors on these ESs and their trade-offs. The results were as follows: (1) the general trend in the SEC of vegetation types was Robinia pseudoacacia $(\mathrm{CH})>$ native grass $(\mathrm{NG})>$ small arbor $(\mathrm{ST})>$ Hippophae rhamnoides $(\mathrm{SJ})>$ artificial grass $(\mathrm{AG})>$ Caragana korshinskii $(\mathrm{NT})>$ apple orchard $(\mathrm{GY})>\operatorname{crop}(\mathrm{CP})$; the $\mathrm{CAS}$ trend was $\mathrm{CH}>\mathrm{SJ}>\mathrm{NT}>\mathrm{AG}>\mathrm{CP}>\mathrm{ST}>\mathrm{GY}>\mathrm{NG}$; and the $\mathrm{SMO}$ trend was $\mathrm{CP}>\mathrm{NG}>\mathrm{GY}>\mathrm{AG}>\mathrm{SJ}$ $>\mathrm{ST}>\mathrm{CH}>$ NT. (2) For SEC-SMO trade-offs, the influence of vegetation type, altitude, silt and sand composition was dominant. The arrangement of NG, AG, and SJ could decrease the extent of the trade-offs. (3) For CAS-SMO trade-offs, vegetation coverage and types were the dominant factors, but the effects were not complex. The extent of these trade-offs was lowest for NT, and that for SJ was the second lowest. (4) Considering the relationships among the three ESs, SJ was the most appropriate afforestation plant. Combing the vegetation types, slope position, slope gradient, and soil properties could regulate these ES relationships. The dominant factors influencing ES
\end{abstract}

\footnotetext{
Abbreviations: SEC, soil erosion control; CAS, carbon sequestration; SMO, soil moisture; SMO1, SMO2, SMO3, SMO4, SMO5, soil moisture in the 0-1 m, 1-2 m, 2-3 m, 3-4 m, and 4-5 m

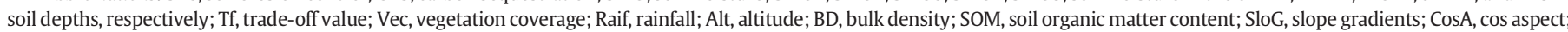

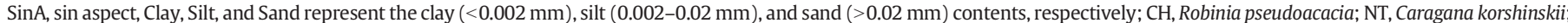

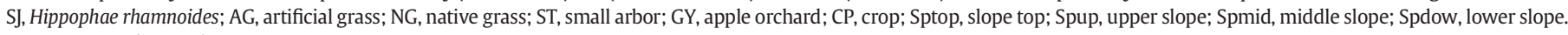
* Corresponding author.

E-mail address: zhaoww@bnu.edu.cn (W. Zhao).
} 
trade-offs varied among the different soil layers, so we must consider the corresponding influencing factors to regulate ESs. Moreover, manual management measures were also important for coordinating the ES relationships. Our research provides a better understanding of the mechanisms influencing the relationships among ESs.

\section{Introduction}

Ecosystem services (ESs) are the benefits that people derive from natural ecological processes (MA, 2005), and they mainly consist of provisioning, regulating, and cultural services that directly affect human well-being, as well as supporting services that maintain the other three (Costanza et al., 1997; Daily, 1997; MA, 2005). People often hope to maximize one or several types of ESs through management, but a principal challenge is that ESs are not independent and may have highly non-linear relationships with unintentional trade-offs resulting due to ignorance of their interactions (Rodriguez et al., 2006). Trade-offs are generally defined as situations in which one ES increases at the cost of another (Bennett et al., 2009; Raudsepp-Hearne et al., 2010); the opposite is synergies, which can be defined as situations in which both services either increase or decrease (Bennett et al., 2009; Haase et al., 2012). In a broader sense, a trade-off also refers to unidirectional changes in ESs at an uneven pace or rate (Lü et al., 2014).

In recent years, trade-off analysis has emerged as a new research field, and previous studies have explored trade-offs among the four types of ESs (provisioning, regulating, cultural and supporting services) (Raudsepp-Hearne et al., 2010; White et al., 2012; Ballantine et al., 2015) and among the subtypes within a given type (e.g., the provisioning of fresh water and food) (Lautenbach et al., 2013; Frank et al., 2014). Trade-off analysis is a key issue when integrating ESs for landscape planning, management, and decision making (Mach et al., 2015; Darvill and Lindo, 2016; Gissi et al., 2016; Wang et al., 2017; Vogdrup-Schmidt et al., 2017), and it has been used to coordinate ESs in various fields, such as agriculture (Lautenbach et al., 2013), tourism (White et al., 2012), energy (Gissi et al., 2016), and ecological restoration (Wang et al., 2017), which encompasses various geographical features around the world, including wetlands (Mach et al., 2015), mountains (Wang et al., 2017), plateaus (Zheng et al., 2016), seaboards (White et al., 2012), and islands (Goldstein et al., 2012). Therefore, trade-off analysis potentially represents a new way to guide ecological restoration on the Loess Plateau of China, where the ecological system is fragile, and water resources are scarce.

The Loess Plateau, which is located in the arid and semi-arid areas of China, experiences significant soil erosion due to intense human activities and soil erodibility. The intense soil erosion threatens the ecological safety and agricultural sustainability of the region (Lü et al., 2007). Furthermore, the sediment that discharges into the Yellow River elevates the riverbed in the lower reaches of the river and increases the risk of flooding. Therefore, the soil erosion control service (SEC) is one of the most fundamental ecosystem service that ensures human welfare in the Loess Plateau. To improve SEC, the Grain-for-Green Program (GFGP) was implemented by the central government at a large scale beginning in 1999 (Chen et al., 2010), and many steep slope croplands have been converted to forested lands and grasslands. After $>10$ years of ecological restoration, the vegetation coverage in the Loess Plateau has obviously increased (Lü et al., 2012), and the average rate of soil erosion decreased from $3362 \mathrm{t} /\left(\mathrm{km}^{2} \cdot \mathrm{a}\right)$ in 2000 to $2405 \mathrm{t} /\left(\mathrm{km}^{2} \cdot \mathrm{a}\right)$ in 2008 . Therefore, the GFGP has effectively enhanced the ecosystem service of soil erosion control (Fu et al., 2011). Furthermore, soil loss is an important source of non-point source pollution in the Loess Plateau (Wu et al., 2015), and it has simultaneously been reduced by the GFGP.

Carbon sequestration (CAS) is an ecosystem process that produces several important ecosystem services, such as provisioning of wood, fiber and fuel, regulating the concentration of greenhouse gases in the atmosphere and mitigating global warming (Upadhyay et al., 2013). The NPP (net primary productivity) and NEP (net ecosystem productivity) in the Loess Plateau have steadily increased since the initiation of the GFGP, with a total of $96.1 \mathrm{Tg}$ of additional carbon sequestered during the period of 2000-2008. The Loess Plateau ecosystem shifted from a net carbon source in 2000 to a net carbon sink in 2008 (Feng et al., 2012).

Although the ecosystem services of soil erosion control and carbon sequestration have improved significantly, the GFGP has had negative effects, one of the most important of which is that local soils have become extremely dry in both the shallow and deeper layers. The two main reasons for this are (1) low precipitation and high evaporation as well as a warming and drying climactic trend (Pu et al., 2006; Fang et al., 2016) and (2) the introduction of vegetation that tends to have greater water consumption needs than the native vegetation (Yang et al., 2014a). Thus, vegetation restoration has often failed due to the lack of soil water, resulting in reductions in vegetation biomass or stunted growth, localized and/or regional vegetation die-off, and poor renewal from a lack of natural germination (Wang et al., 2004a; Wang et al., 2008). In particular, the thickness of the loess soil in this area ranges from 30 to $80 \mathrm{~m}$, depths at which groundwater is not available for plants (Wang Y.Q. et al., 2013), so the soil moisture (SMO) stored in shallow (influenced by rainfall infiltration and evapotranspiration) and deep layers (below the annual rainfall infiltration depth) is critical for plant growth and serves as a key water source for sustaining the ecosystems in this region (Chen et al., 2008; Yang et al., 2012). Therefore, soil moisture is the basis for vegetation restoration, and vegetation cover is the basis for soil erosion control, carbon sequestration, and biodiversity. In this sense, we can treat soil moisture as a supportive service. Moreover, soil moisture is the most important variable regulating many ecosystem processes in water-limited landscapes (Asbjornsen et al., 2011), and soil desiccation has a negative effect on these processes. Thus, soil moisture is a scarce regulating service.

Soil erosion control, carbon sequestration and soil moisture are the three most important ESs in the Loess Plateau. After $>10$ years of vegetation restoration, the ESs of soil erosion control (Fu et al., 2011) and carbon sequestration (Feng et al., 2012) have been enhanced, whereas soil moisture has decreased (Wang et al., 2010). If soil desiccation continues, the achievements related to soil erosion control and carbon sequestration will be lost because of vegetation degeneration, and therefore, coordinating the relationship among the three ESs is an immediate problem both theoretically and practically. Previous research has qualitatively explored the relationships among the ESs on the Loess Plateau of China including water yield, crop production, water conservation, soil erosion control, carbon sequestration, and biodiversity (Su et al., 2012a; Hou et al., 2014; Jia et al., 2014; Lü et al., 2014; Zheng et al., 2014). However, the relationships between deep soil moisture and both soil erosion control and carbon sequestration have not been clarified, and very few researchers have paid attention to quantifying the extent of the trade-offs among the ESs (Lü et al., 2014; Zheng et al., 2016). Furthermore, the effects of environmental factors on the ES trade-offs have not been clarified. Thus, the existing theoretical knowledge is insufficient for the management of various ESs.

In this study, we estimated three ESs (soil erosion control, carbon sequestration and soil moisture $(0-5 \mathrm{~m})$ ) based on field observations in the Ansai watershed. Feng et al. (2012) found insignificant changes in soil carbon storage after nearly ten years of vegetation restoration, so we estimated only the carbon storage by the vegetation. We also 
measured environmental factors. The objectives of this study were to (1) determine the effects of environmental factors on ESs, (2) quantify the extent of trade-offs among ESs and explore the mechanisms underlying the influence of environmental factors on trade-offs, and (3) develop recommendations for land-use planning and ecological restoration on the Loess Plateau.

\section{Materials and methods}

\subsection{Study area}

The Yanhe watershed lies in the middle of the Loess Plateau in northern Shaanxi Province, and the sub-watershed examined in this study is in the upstream section of the Yanhe and is controlled by the "Ansai" hydrometric station $\left(109^{\circ} 19^{\prime} \mathrm{E}, 36^{\circ} 52^{\prime} \mathrm{N}\right)$. For convenience, the region is referred to as the Ansai watershed $\left(108^{\circ} 47^{\prime}-109^{\circ} 25^{\prime} \mathrm{E}, 36^{\circ} 52^{\prime}-37^{\circ} 19^{\prime}\right.$ $\mathrm{N}$ ), which covers an area of $1334 \mathrm{~km}^{2}$ (Fig. 1), it has a typical semiarid continental climate with an average temperature of $8.8^{\circ} \mathrm{C}$ and an average annual precipitation of $505 \mathrm{~mm}$. Rainfall shows high seasonal variability, with $>60 \%$ of the annual precipitation occurring between July and September. The Ansai watershed is located on a warm forest steppe where natural forests have been destroyed, but there are numerous artificial plantings of predominantly Robinia pseudoacacia (tree), Armeniaca sibirica (small arbor), Amygdalus davidiana (small arbor), Caragana korshinskii (shrub), Hippophae rhamnoides (shrub), and Medicago sativa (artificial grass). The native grasses are mainly composed of Poa sphondylodes, Lespedeza davurica, and Stipa bungeana. Additionally, there are orchards with mainly apple trees, and the main crops are maize, millet and broom corn millet. These crops were in the booting stage at the beginning of the study and were growing well at the time of sampling.

\subsection{Sampling design}

The fieldwork was conducted from July 10, 2014 to August 15, 2014. We selected sample plots in eight vegetation types: artificial grass (AG), native grass (NG), crop (CP), apple orchard (GY), Caragana korshinskii (NT), Hippophae rhamnoides (SJ), small arbor (ST), and Robinia pseudoacacia $(\mathrm{CH})$. Each vegetation type covered a certain area (>30 $\mathrm{m} \times 30 \mathrm{~m}$ ) with a sample plot $(20 \mathrm{~m} \times 20 \mathrm{~m})$ in the center, and a total of $11 \mathrm{AG}, 25 \mathrm{NG}, 22 \mathrm{CP}, 10 \mathrm{GY}, 18 \mathrm{NT}, 15 \mathrm{SJ}, 12 \mathrm{ST}$, and $38 \mathrm{CH}$ plots were surveyed (Fig. 1). Their coordinates were recorded using GPS receivers (Trimble GeoExplorer 2008 Series GeoXH, Sunnyvale, USA) with a deviation of $<1 \mathrm{~m}$.

\subsection{Measurement of environmental factors}

The vegetation coverage ( $\mathrm{Vec}$ ) was obtained as follows. A Pentax $15-$ $\mathrm{mm} \mathrm{f} / 2.8$ camera was placed beneath the canopy (tree, shrub, and orchard) facing upwards, which allowed for better discrimination of the leaves based on the contrast between the vegetation and the sky. Fifteen photographs were taken along the diagonal plot line at 3-m intervals and then processed through ENVI 5.1 to obtain the vegetation coverage. The grass and crop coverage were also estimated using digital photos, although a slightly different method was used; the camera was placed above the ground at a height of $3 \mathrm{~m}$ looking downwards rather than upwards. For vegetation types that had two or more layers (such as NT,

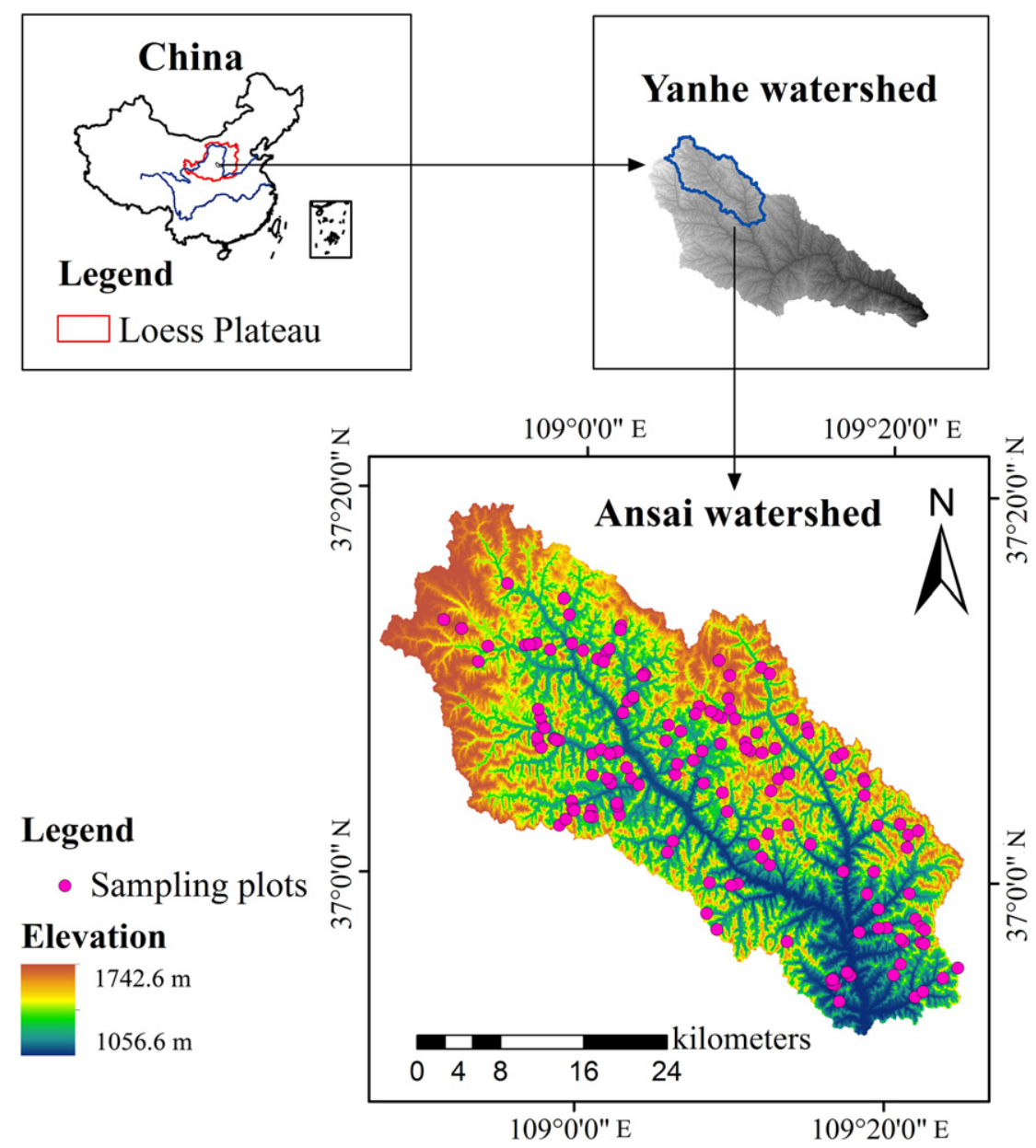

Fig. 1. Study area and locations of the sampling plots. 
which had both shrub and grass layers), the sum of the coverage of every layer represented Vec.

In each sampling plot, six undisturbed soil cores were collected from the soil surface in metal cylinders (diameter of $5.046 \mathrm{~cm}$, length of $5 \mathrm{~cm}$ ) to measure the bulk density (BD), and five soil samples were also collected. The soil particle size distributions were measured using a laser scattering particle size distribution analyzer (BT-9300H, Dandong, China), and the proportions of clay $(<0.002 \mathrm{~mm})$, silt $(0.002-$ $0.02 \mathrm{~mm}$ ), and sand $(>0.02 \mathrm{~mm})$ were then calculated. The soil organic matter (SOM) content was determined using the dichromate oxidation method (Nelson and Sommer, 1975).

The altitude (Alt) of each experimental plot was determined using GPS receivers, and the slope gradients (SloG) were determined using the compass method. True north was $0^{\circ}$, the slope aspect was the clockwise rotational angle and was measured using a compass; and the slope aspects were transformed into the cos aspects (CosA) and $\sin$ aspects $(\operatorname{Sin} A)$. The positions of the sample plots on the slope were also recorded, which included the slope top (Sptop), upper slope (Spup), middle slope (Spmid), and lower slope (Spdow).

The multi-year average rainfall data (2006-2014) were provided by 29 rain gauges in or around the Ansai watershed, and the inverse distance-weighted (IDW) interpolation method was performed in ArcGIS10.0 to obtain the rainfall (Raif) for each sampling plot.

\subsection{Quantification of ESs}

\subsubsection{Soil erosion control (SEC)}

Soil loss was estimated by the Revised Universal Soil Loss Equation (RUSLE) (Renard et al., 1997), as follows:

$A=R \times K \times L \times S \times C \times P$

where $A$ is the estimated average soil loss; $R$ is the rainfall erosivity factor; $K$ is the soil erodibility factor; $L$ is the slope length factor; $S$ is the slope steepness factor; $C$ is the cover and management factor; and $P$ is the support practice factor.

If there is no vegetation coverage or support practice, $C$ and $P$ are assigned a value of 1 . Then, the calculated soil erosion becomes the potential soil loss $\left(A_{\mathrm{p}}\right)$ :

$A_{\mathrm{p}}=R \times K \times L \times S$

The amount of soil erosion control (SEC) can be calculated as the difference between the potential soil loss $\left(A_{\mathrm{p}}\right)$ and the actual soil loss (A) as follows:

$\mathrm{SEC}=A_{\mathrm{p}}-A=R \times K \times L \times S \times(1-C \times P)$

The rainfall erosivity factor $(R)$ was calculated using the empirical formula established for China (Zhang and Fu, 2003), and the soil erodibility factor $(K)$ was calculated using the method of Williams et al. (1984). The slope length factor $(L)$ was calculated using formulas from the literature (Foster et al., 1977; Wischmeier and Smith, 1978; McCool et al., 1989), and the slope steepness factor $(S)$ was calculated using the formulas from McCool et al. (1987) and Liu et al. (1994) for gentle and steep slopes, respectively, which was suitable for the Loess Plateau of China. The cover and management factor $(C)$ was computed as a product of five sub-factors following the RUSLE handbook (Renard et al., 1997). Most of the croplands and some of the apple orchards were terraced, and the support practice factor $(P)$ value was assigned to a corresponding slope gradient according to the $P$ value table in the RUSLE handbook (Renard et al., 1997). The support practices were not conducted for the other vegetation types, and the $P$ value was 1 .

\subsubsection{Carbon sequestration (CAS)}

In the AG and NG sample plots, five quadrats $(1 \mathrm{~m} \times 1 \mathrm{~m})$ were selected along the diagonal plot line at 5-m intervals; the litter and aboveground grass in each quadrat were collected in a large envelope, respectively; and the corresponding biomass was determined via oven drying at $65^{\circ} \mathrm{C}$ to a constant weight.

In the NT and SJ sample plots, based on plant height and canopy width of each individual, three standard trees were selected to represent the average level of the individual, and the aboveground biomass was measured via the oven-drying method. The litter biomass was also determined with the method conducted in AG.

For the above four vegetation types, the underground biomass was estimated from the aboveground-underground biomass ratio, which was $0.21 / 1$ for herbaceous plants (AG and NG) and 1.1/1 for shrubs (NT and SJ) (Liu et al., 2011).

In each $\mathrm{CH}, \mathrm{ST}$, and GY sample plot, the height $(\mathrm{H})$ and diameter at breast height $(\mathrm{DBH})$ of each individual plant was measured. The plant biomass was estimated as the sum of the biomass of different plant components, including the stem, branch, leaf, root, and bark, based on the biometric equations from $\mathrm{H}$ and DBH (Shen and Zhang, 2014). The litter biomass was also determined using the method for AG.

In the $\mathrm{CP}$ sample plot, the height and stem diameter of the crop were similar. After measuring the planting density, three crops were cut; the roots were excavated; and the biomass was measured via the ovendrying method. There was no litter under conventional tillage, which is typical of this region.

The vegetation carbon storage was determined as the product of the biomass and carbon content. The carbon content of $\mathrm{CH}$, GY and ST was 0.5 ; for shrubs ( $\mathrm{SJ}$ and NT), it was 0.49 ; and for herbaceous plants (AG, $\mathrm{NG}$, and $\mathrm{CP}$ ) and litter, it was 0.40 and 0.39 , respectively (Ma et al., 2002). The sum of the plant and litter carbon storage represented the vegetation carbon sequestration (CAS).

\subsubsection{Soil moisture (SMO)}

Only one large rainfall event (rainfall $=50.6 \mathrm{~mm}$ ) occurred during the later period of field work (August 6); no other rainfall event was larger than $9.4 \mathrm{~mm}$. Therefore, the influence of rainfall events on the soil moisture was small and acceptable during sampling period.

The soil samples were collected from depths of $0-5 \mathrm{~m}$ using a soil drill ( $5 \mathrm{~cm}$ in diameter) at $20-\mathrm{cm}$ increments. The soil samples were sealed and taken to the laboratory, and the gravimetric soil moisture content was determined via oven drying to a constant weight at 105 ${ }^{\circ} \mathrm{C}$. Three sampling profiles were randomly chosen to obtain the average soil moisture content for each sampling plot.

The SMO was divided into five depths (0-1 m, 1-2 m, 2-3 m, 3-4 m and $4-5 \mathrm{~m}$ ), and the average SMO of each depth was calculated using the aforementioned soil moisture data. The entire SMO (the average soil moisture value of the $0-5$ m layers) was also analyzed in this study.

\subsection{Calculation of the ESs trade-offs}

One simple but effective mean for quantifying the magnitude of the trade-offs between two or more ESs is to calculate the root mean squared error (RMSE) of the individual ESs (Bradford and D'Amato, 2012). In two dimensions, the RMSE represents the distance from the coordinates of an ES pair to the 1:1 line, and the position of a data point relative to the line indicates which ES is more beneficial (Fig. 2). This method extends the meaning of trade-off from a negatively correlated relationship (i.e., the traditional sense) to the inclusion of uneven rates of same-direction changes between ESs. Lü et al. (2014) used this method to explore the ES trade-offs along a precipitation gradient across the landscapes of the Loess Plateau. 


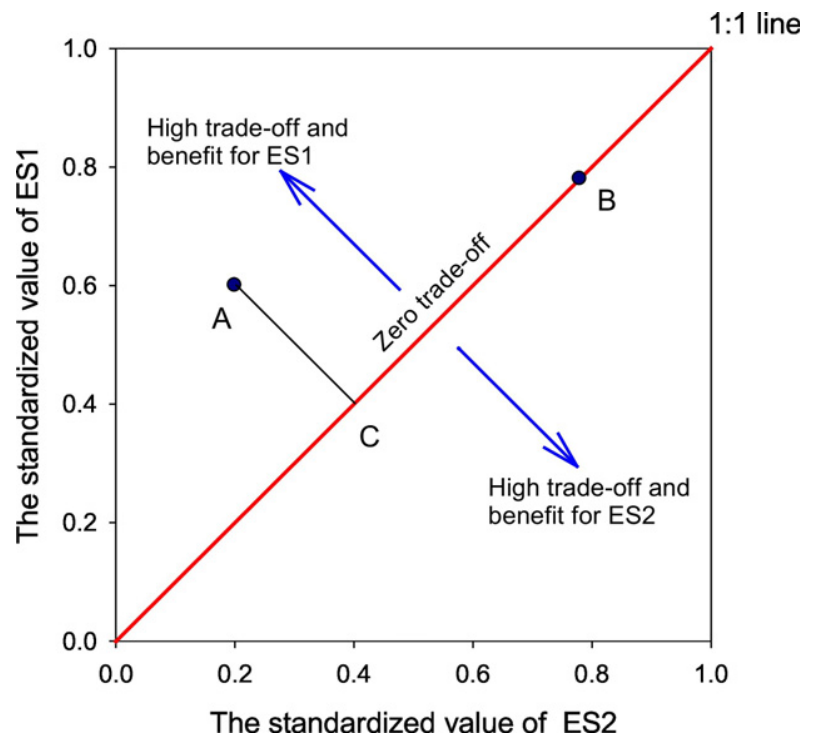

Fig. 2. Illustration of the trade-offs between two ecosystem services (ESs). The RMSE is the distance from the coordinates of a pair of ESs to the 1:1 line, where the two ESs are equal. For example, the trade-off value is zero for point $B$, and the length of line segment $A C$ represents the trade-off value of point $A$. This figure is modified from Bradford and D'Amato (2012) and Lü et al. (2014).

Data standardization was required before the RMSE was calculated. Following Bradford and D'Amato (2012), the standardized ES, or the relative benefit of an ES, is defined as follows:

$\mathrm{ES}_{\mathrm{std}}=\left(\mathrm{ES}_{\mathrm{obs}}-\mathrm{ES}_{\min }\right) /\left(\mathrm{ES}_{\max }-\mathrm{ES}_{\min }\right)$

where $\mathrm{ES}_{\text {std }}$ is the standardized value of any $\mathrm{ES} ; \mathrm{ES}_{\mathrm{obs}}$ is an observed value; and $\mathrm{ES}_{\min }$ and $\mathrm{ES}_{\max }$ are the minimum and maximum observed values.

RMSE $=\sqrt{\frac{1}{n-1} \sum_{i=1}^{n}\left(E S_{i}-\overline{E S}\right)^{2}}$

where $\mathrm{ES}_{\mathrm{i}}$ is the standardized value of $\mathrm{ES} \mathrm{i}$, and $\overline{\mathrm{ES}}$ is the expected value of the i number of ESs. In a two-dimensional coordinate system, $\overline{\mathrm{ES}}$ is on the $1: 1$ line.

\subsection{Statistical analyses}

The descriptive statistics of the SEC, CAS, entire SMO (the average value of SMO in $0-5 \mathrm{~m}$ ), and the SMO of each depth were calculated for each vegetation type. Pearson's correlation analysis was performed among the three ESs to identify their relationships.

A multivariate analysis was performed to explore the influence of the environmental factors (topography (slope position, SloG, CosA, and SinA), soil (Clay, Silt, Sand, SOM, and BD), vegetation (vegetation type and Vec), and Raif) on the ESs and ESs trade-offs. To determine whether linear or unimodal numerical methods should be used, detrended correspondence analysis (DCA) was conducted. In this study, the largest DCA gradient length values were all shorter than 3.0; thus, a redundancy analysis (RDA) was applied. A Monte Carlo permutation test based on 499 random permutations was conducted to test the significance of the eigenvalues of all canonical axes as well as the significance of the marginal and conditional effects.

The descriptive statistics were calculated and the correlation analysis was conducted using IBM SPSS (version 20, Chicago, USA), and the RDA was performed using CANOCO (version 5.0, Ithaca, USA). The graphs were drew using SigmaPlot (version 10, Chicago, USA).

\section{Results and discussion}

\subsection{The physical quantities of ESs}

As illustrated in Fig. 3, the general trend in the mean SEC value for the various vegetation types was $\mathrm{CH}>\mathrm{NG}>\mathrm{ST}>\mathrm{SJ}>\mathrm{AG}>\mathrm{NT}>\mathrm{GY}$ $>\mathrm{CP}$. The soil conservation capability of NG was higher than that of shrub (SJ and NT) and ST, which differed from the general understanding, although similar results have often been obtained (Nunes et al., 2011; Wang F. et al., 2013). The stratified structures of some shrub and ST plots were simple, with good canopy cover but poor grass cover. In such cases, the rainfall and runoff directly erode exposed soil, and therefore, the SEC was always low. Furthermore, the rainfall intercepted by shrub and ST may fall to the soil from certain height as larger raindrops, which can exacerbate soil erosion. The results demonstrated that the stratified structure must be considered in vegetation restoration. Vegetation with a completely stratified structure favors SEC and the mitigation of non-point source pollution.

The trend in the mean CAS value was $\mathrm{CH}>\mathrm{SJ}>\mathrm{NT}>\mathrm{AG}>\mathrm{CP}>\mathrm{ST}$ $>\mathrm{GY}>\mathrm{NG}$, whereas the median value of AG was lower than that of ST and GY. The NG was mainly composed of low-biomass plants such as Artemisia capillaries, Stipa bungeana and Poa annua, so its CAS was the lowest.

Wang et al. (2004b) divided the degree of soil desiccation into three levels: severe (soil water content below $0.05 \mathrm{~g} / \mathrm{g}$ ), moderate (soil water content ranging between 0.05 and $0.08 \mathrm{~g} / \mathrm{g}$ ), and slight (soil water content ranging between 0.08 and $0.10 \mathrm{~g} / \mathrm{g}$ ), which can be represented by three colored lines for various vegetation types (Fig. 3). The trend in the mean SMO value for the entire soil layer (0-5 m) was $\mathrm{CP}>\mathrm{NG}$ $>\mathrm{GY}>\mathrm{AG}>\mathrm{SJ}>\mathrm{ST}>\mathrm{CH}>\mathrm{NT}$. Most of the $\mathrm{CP}$ that we surveyed was on level terraces and back-slope level benches under cultivation, which were conducive to water infiltration, and the SMO was high. The introduced deep-rooted plants ( $\mathrm{CH}$ and $\mathrm{NT}$ ) consumed the most soil water and induced moderate soil desiccation. Comparatively, NG favored soil water maintenance.

We divided the soil into five equal layers. In AG, the SMO in the 0$1 \mathrm{~m}$ layer was the second lowest among the various vegetation types; in the 1-2 m layer, the SMO was the lowest compared to the other layers; and at the depth of $2-5 \mathrm{~m}$, the SMO relatively increased as the depth increased. The SMO of $\mathrm{CH}$ and ST in the $0-1 \mathrm{~m}$ layer was in the middle range of the vegetation types, and severe soil desiccation did not occur in any sample plot. However, in the 2-5 m depth, the SMO values of $\mathrm{CH}$ and ST were relatively low among the vegetation types, and the sample plots of severe soil desiccation were found in every soil layer. The SMO of NT was very low in every soil layer compared to the other vegetation types.

In conclusion, the root distributions influenced soil water consumption (the root distributions of the various vegetation types can be seen in the Supplementary material), and the water consumption characteristics influenced SMO, a basic ES. The water consumption of $\mathrm{CP}, \mathrm{NG}$ and GY were low; AG mainly consumed shallow soil water; $\mathrm{CH}$ and NT mainly consumed deep soil water; the water consumption of NT was high in every layer; the water consumption performance of SJ was eclectic, and deep soil water consumption was not high. Our results are similar to those of previous studies; NT and $\mathrm{CH}$ caused soil desiccation (Wang et al., 2010; Wang et al., 2011; Yang et al., 2012; Yang et al., 2014a, 2014b; Fang et al., 2016; Liu et al., 2016). The dried soil layer prevented the interchange of water between the upper soil layers and the groundwater, which is often considered to negatively affect the water cycle (Li and Huang, 2008; Wang Y.Q. et al., 2013).

\subsection{Understanding the relationship between ESs and environmental factors}

\subsubsection{Overall analysis of the three ESS}

The eigenvalues of the four RDA axes and their explained variance derived from the data matrices are shown in Table 1 . The overall test 

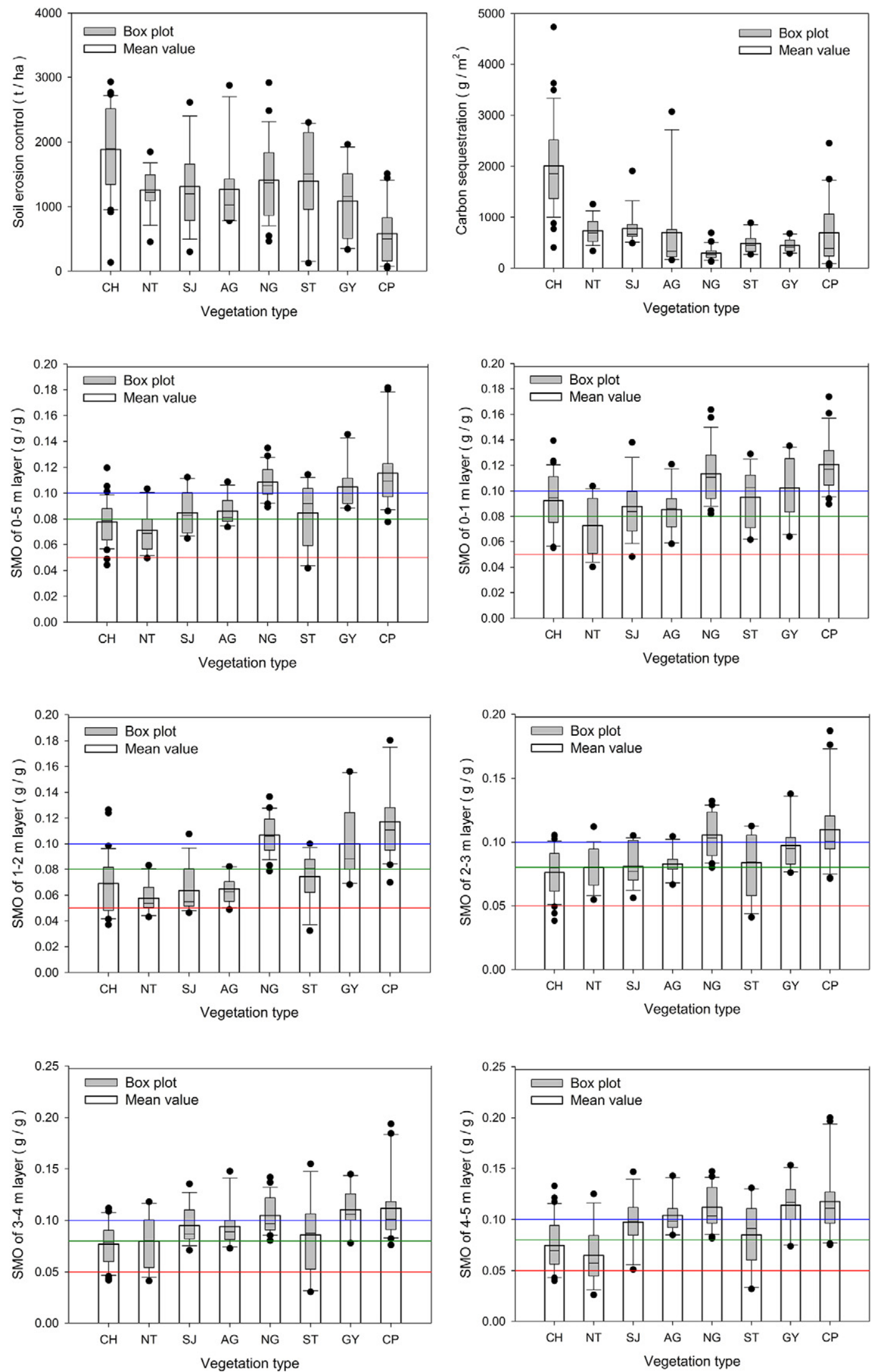

Fig. 3. Descriptive statistics of the physical quantities of ESs (the red, green, and blue lines represent soil water contents of $0.05 \mathrm{~g} / \mathrm{g}$, $0.08 \mathrm{~g} / \mathrm{g}$, and $0.10 \mathrm{~g} / \mathrm{g}$, respectively). 
Table 1

Eigenvalues and explained variance of the redundancy analysis axes for the ESs.

\begin{tabular}{lllll}
\hline & Axis 1 & Axis 2 & Axis 3 & Axis 4 \\
\hline Eigenvalues & 0.4794 & 0.1273 & 0.0846 & 0.1288 \\
Explained variation (cumulative, \%) & 47.94 & 60.67 & 69.12 & 82.01 \\
Permutation test on all axes & $P=0.002$ & & & \\
\hline
\end{tabular}

of the canonical relationship was significant; the cumulative percent variance in the ESs that was explained on the first two axes of the RDA was 60.67\%. As illustrated in Fig. 4, the environmental factors that were highly positively correlated with the first ordination axis were Vec, SloG, vegetation type ( $\mathrm{CH}$ and NT) and SOM, and those that were highly negatively correlated were vegetation type (NG and CP), Alt, Silt, BD and slope position (Sptop).

3.2.2. Marginal and conditional effects of environmental factors on each ESS

Table 2 shows the changing conditions of marginal and conditional effects of the environmental variables under the Monte Carlo test in the process of forward selection. The marginal effects reflected the effects of the environmental variables on the ESs, but the conditional effects reflected the effects of the environmental variables on the ESs after the anterior variable was eliminated.

Only the variables that had significant $(p<0.05)$ effects on SEC are listed in Table 2. The marginal effect of SloG was the highest (36.9\%), and that of Vec was second highest (30.3\%). The soil conservation capability of $\mathrm{CH}$ was the strongest, whereas those of $\mathrm{CP}$ and GY were the lowest. Therefore, the marginal or conditional effects of these three vegetation types were significant. There was a strong correlation between Vec and vegetation type, so after vegetation type (CP) was put forward under the Monte Carlo test, the conditional effect of Vec was not significant. The marginal and conditional effects of Raif were the lowest.

As illustrated in Table 3, Vec and vegetation type were the best explanatory variables for CAS; the marginal effect of Vec reached $50.2 \%$. Other factors, such as the soil physical and chemical properties, Alt, and SloG, also influenced CAS by vegetation type.

As illustrated in Table 4, the explanatory capability of the environmental factors for the entire SMO (0-5 m) was considerably below those for SEC and CAS individually. The explanatory capability of Vec was highest, but the marginal effects value was only $18.5 \%$. The conditional effects of Alt and CosA were significant, indicating that both the north-south change in the slope aspect and the height had an important influence on SMO. The conditional effects of SloG, Clay, Silt, and SOM were not significant, indicating that interaction effects existed between them and other environmental variables.

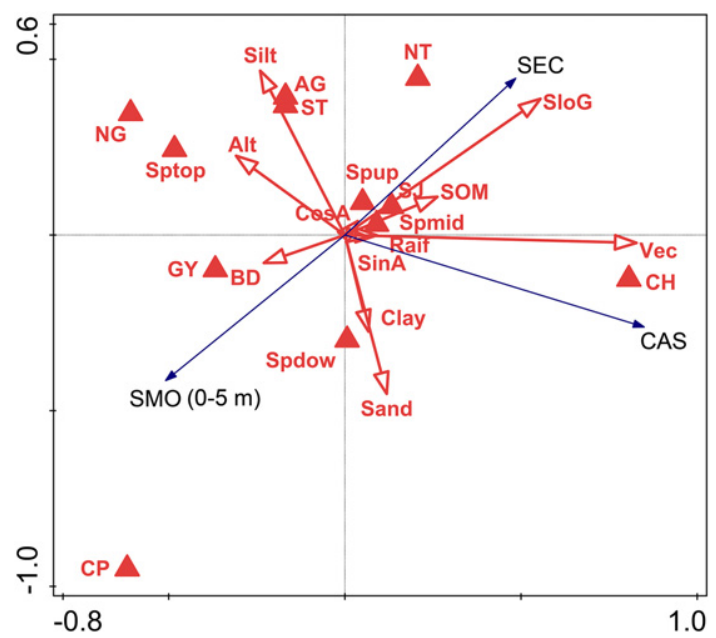

Fig. 4. Biplot diagram for the RDA between the ESs and environmental factors.
Table 2

Marginal and conditional effects from the summary of forward selection for SEC.

\begin{tabular}{lll}
\hline Variables & Marginal effects (\%) & Conditional effects (\%) \\
\hline SloG & 36.9 & 36.9 \\
CP & 30.3 & 11 \\
Vec & 13.9 & - \\
CH & 11 & - \\
BD & 5.2 & - \\
Alt & 5 & - \\
Raif & 3.8 & 1.6 \\
Spup & - & 1.6 \\
GY & - & 1.6 \\
\hline
\end{tabular}

"-" Indicates that the marginal or conditional effect is not significant.

The explanatory capability of various vegetation types for SMO changed as soil depth increased. The conditional effects of $\mathrm{CP}$ and NG were highest compared with other vegetation types in the $0-1 \mathrm{~m}$ and 1-2 m soil layers, whereas that of $\mathrm{CH}$ was not significant. In the 2-3 m soil layer, the conditional effect of $\mathrm{CH}$ was highest (18.3\%) and the influence of CP and NG was still significant, but the conditional effect was lowest. The conditional effects of $\mathrm{CP}$ and NG were not significant, but those of $\mathrm{CH}$, NT and ST were significant for the 3-4 $\mathrm{m}$ soil layer. The trend in the conditional effect value was $\mathrm{CH}>\mathrm{NT}>\mathrm{ST}>\mathrm{SJ}$. Therefore, herbaceous plants controlled SMO in the upper soil layer, whereas woody plants controlled SMO in the deeper soil layer.

\subsubsection{Identifying the relationships between ESs}

As illustrated in Table 5, the SEC was significantly positively correlated with CAS, and it was significantly negatively correlated with SMO in the $0-5 \mathrm{~m}, 0-1 \mathrm{~m}, 1-2 \mathrm{~m}$ and $4-5 \mathrm{~m}$ soil layers. CAS was significantly negatively correlated with SMO in every soil layer, except for 0-1 m.

The synergies between SEC and CAS were determined, and the soil conservation capability increased as carbon sequestration increased. The trade-offs between SEC and SMO were strong in the $0-2 \mathrm{~m}$ soil layer. The trade-offs between CAS and SMO were weakest in the shallow soil layer (0-1 $\mathrm{m}$ ) and strongest in the deep soil layer (4-5 m), indicating that CAS increased at the cost of decreasing the SMO in the deep layer.

\subsubsection{Quantifying and illustrating the trade-offs between ESS}

As illustrated in Fig. 5, the SEC and SMO (0-5 m) of NG and AG mostly fell around the 1:1 line in the scatter plot, suggesting a very coordinated relationship between the two ESs. Conflicts existed between SEC and SMO in CH, NT, SJ and ST; the data points deviated from the 1:1 line toward to SEC, especially in $\mathrm{CH}$, indicating that the increase in SEC was accompanied by SMO consumption. The manually managed GY and CP did not favor SEC, but SMO was relatively high.

Table 3

Marginal and conditional effects from the summary of forward selection for CAS.

\begin{tabular}{lll}
\hline Variables & Marginal effects (\%) & Conditional effects (\%) \\
\hline Vec & 50.2 & 50.2 \\
CH & 46.1 & 19.5 \\
NG & 19 & - \\
SloG & 14 & - \\
Silt & 11 & - \\
Alt & 10.6 & - \\
Sptop & 6.6 & 1.2 \\
Sand & 5.1 & - \\
SOM & 3.8 & - \\
CP & 3.5 & 2.7 \\
BD & 3.1 & - \\
AG & - & 1.8 \\
SJ & - & 1.3 \\
NT & - & 1.3 \\
\hline
\end{tabular}

\footnotetext{
"-" Indicates that the marginal or conditional effect is not significant.
} 
Table 4

Marginal (MarE) and conditional effects (ConE) obtained from the summary of forward selection for SMO.

\begin{tabular}{|c|c|c|c|c|c|c|c|c|c|c|c|c|}
\hline \multirow[t]{2}{*}{ Variables } & \multicolumn{2}{|l|}{$0-5 \mathrm{~m}$} & \multicolumn{2}{|l|}{$0-1 \mathrm{~m}$} & \multicolumn{2}{|l|}{$1-2 \mathrm{~m}$} & \multicolumn{2}{|l|}{$2-3 \mathrm{~m}$} & \multicolumn{2}{|l|}{$3-4 \mathrm{~m}$} & \multicolumn{2}{|l|}{$4-5 \mathrm{~m}$} \\
\hline & MarE & ConE & MarE & ConE & MarE & ConE & MarE & ConE & MarE & ConE & MarE & ConE \\
\hline Vec & 18.5 & 18.5 & 12.9 & - & 27.3 & 27.3 & 12.5 & 6.3 & 7.1 & - & 12.4 & 12.4 \\
\hline $\mathrm{CP}$ & 16.9 & - & 13.2 & 13.2 & 23.1 & 9.7 & 12.7 & 3.9 & 8 & - & 9.1 & - \\
\hline Sand & 11.2 & 14.3 & 7.2 & - & 14.2 & 18.4 & 14.9 & 14.9 & 6.7 & 12 & 3.3 & 6.2 \\
\hline $\mathrm{CH}$ & 10.4 & 6.6 & - & - & 7.1 & - & 10.7 & 18.3 & 11.7 & 11.7 & 11.7 & 11.5 \\
\hline NG & 10.4 & - & 7.3 & 11.8 & 13.5 & 4.1 & 9.5 & 3 & 3.9 & - & 6.4 & - \\
\hline NT & 9.6 & 5.8 & 12.4 & 4.3 & 9.7 & - & - & - & 3.2 & 5.8 & 11 & 5.2 \\
\hline Clay & 8.1 & - & 10.9 & 8.1 & 11.1 & - & 10.2 & - & 2.8 & - & - & - \\
\hline SloG & 7.4 & - & 4.9 & - & 5.8 & - & 2.9 & - & 6.1 & - & 8.2 & - \\
\hline Silt & 6.9 & - & 6.4 & - & 10.6 & - & 9.7 & - & 3.2 & - & - & - \\
\hline SOM & 3.9 & - & 5.5 & - & 3.2 & - & - & - & - & - & 5.1 & - \\
\hline Alt & - & 3.4 & - & - & - & 1.7 & 4.9 & 5.1 & - & 2.5 & - & - \\
\hline ST & - & 3 & - & - & - & - & - & - & - & 3 & - & 3.8 \\
\hline AG & - & 1.8 & - & - & - & - & - & - & - & - & - & - \\
\hline SJ & - & 1.4 & - & - & 4.6 & - & - & - & - & - & - & 1.7 \\
\hline $\operatorname{Cos} \mathrm{A}$ & - & 1.4 & - & - & - & 1.1 & - & - & - & - & - & - \\
\hline Spdow & - & - & 7.7 & - & - & - & - & - & - & - & - & - \\
\hline Spup & - & - & - & - & 3.1 & - & - & - & - & - & - & - \\
\hline GY & - & - & - & - & 2.5 & 3.2 & - & - & 3 & - & 2.8 & - \\
\hline Raif & - & - & - & - & - & - & 3.6 & - & 2.6 & - & - & - \\
\hline $\operatorname{Sin} A$ & - & - & - & - & - & - & - & - & - & 1.8 & - & - \\
\hline
\end{tabular}

“-" Indicates that the marginal or conditional effect is not significant.

The trend in the trade-off values between SEC and SMO was $\mathrm{CH}>\mathrm{CP}$ $>\mathrm{ST}>\mathrm{NT}>\mathrm{GY}>\mathrm{SJ}>\mathrm{NG}>\mathrm{AG}$, so the selection of NG, AG and $\mathrm{SJ}$ was appropriate for ecological restoration in the Ansai watershed if only the relationship between SEC and SMO was considered. Afforestation by predominantly introduced vegetation (e.g., $\mathrm{CH}, \mathrm{NT}$ ) was not appropriate; for instance, the water consumption effect of $\mathrm{CH}$ was close to the soil erosion effect of $\mathrm{CP}$. The choice of GY represented a balance between rural economy and revegetation, as agricultural cultivation measures, such as straw mulching, and water retention agents can be applied to compensate for the lack of soil conservation.

As illustrated in Fig. 6, for CAS and SMO (0-5 m), NG, AG, SJ, ST, GY and $\mathrm{CP}$ favored SMO, but CAS was relatively low. The data points for the two ESs in NT fluctuated around the 1:1 line. $\mathrm{CH}$ had the absolute advantage in terms of CAS, so the CAS values of the other vegetation types were all relatively low.

The trend in the trade-off values between CAS and SMO was NG $>\mathrm{CP}$ $>\mathrm{GY}>\mathrm{AG}>\mathrm{ST}>\mathrm{CH}>\mathrm{SJ}>\mathrm{NT}$, which was very different from that between SEC and SMO. The trade-off value between the SEC and SMO of NG was the second lowest, but that between CAS and SMO was highest. Grassland and cropland had higher soil moisture but lower biomass. Therefore, the extent of the trade-offs between the two ESs was high (SMO increased at the cost of decreasing CAS).

The trade-off values between the CAS and SMO of NT and SJ were the smallest, but considering the relationship between SEC and SMO, NT was inclined toward severe soil water consumption. Many previous researchers found that NT resulted in soil desiccation and impacted the sustainability of vegetation recovery in the Loess Plateau (Wang et al., 2010; Wang et al., 2011; Yang et al., 2012; Yang et al., 2014a, 2014b; Fang et al., 2016; Liu et al., 2016), and thus, NT was not an appropriate afforestation plant in the GFGP.

Considering the overall relationship among the three ESs, SJ was an appropriate selection for ecological restoration because it could balance the three ESs. NG was suitable for growing in places where soil water conditions were poor, so it was a preferred vegetation type when the demand for CAS was not urgent. GY and ST did not induce severe conflicts among the three ESs; therefore, they could be flexibly planted among other vegetation types in combination with artificial management measures.

\subsubsection{Redundancy analysis (RDA) of the SEC-SMO trade-off and environ- mental factors}

The cumulative percentage variance in the SEC-SMO trade-offs explained on the first two RDA axes was 37.68\% (Table 6). As illustrated in Fig. 7, the arrow representing the trade-offs between SEC and shallow (0-1 $\mathrm{m})$ SMO was in the first quadrant, but those between SEC and the SMO of the other layers were in the fourth quadrant, indicating the complexity and specificity of shallow SMO. The environmental variables that were highly positively correlated with the first ordination axis were Sand, Clay, vegetation type $(\mathrm{CH})$, and SloG, and those that were highly negatively correlated with the first ordination axis were Silt, Alt, slope position (Spup), and vegetation type (NG and AG).

The environmental variables that significantly $(p<0.05)$ affected the SEC-SMO trade-offs are listed in Table 7. In summary, the number of environmental variables that had significant conditional effects was far less than the number that had significant marginal effects, which indicated that strong interaction effects existed among the environmental variables. For the entire soil layer (0-5 m), the marginal effects of Silt, Sand, vegetation type $(\mathrm{CH})$ and Alt were higher than $10 \%$. The conditional effect of Silt was highest (14.5\%), but those of the other environmental variables were all lower than $8 \%$.

The analysis of each soil layer was as follows. The explanatory capability of the environmental variables for the SEC-SMO (0-1 m) trade-off was relatively low; the marginal and conditional effects were all below $9 \%$. This phenomenon suggests that the relationship between the two ESs in the shallow soil layer was more complex and that they were influenced by many factors, and that the number of selected environmental

Table 5

Pearson's correlation analysis between ecosystem services.

\begin{tabular}{|c|c|c|c|c|c|c|c|c|}
\hline & SEC & CAS & $\mathrm{SMO}$ in $0-5 \mathrm{~m}$ & $\mathrm{SMO}$ in $0-1 \mathrm{~m}$ & $\mathrm{SMO}$ in $1-2 \mathrm{~m}$ & SMO in $2-3 \mathrm{~m}$ & $\mathrm{SMO}$ in $3-4 \mathrm{~m}$ & $\mathrm{SMO}$ in $4-5 \mathrm{~m}$ \\
\hline SEC & 1 & $0.398^{* *}$ & $-0.178^{*}$ & $-0.178^{*}$ & $-0.214^{* *}$ & -0.092 & -0.106 & $-0.167^{*}$ \\
\hline CAS & $0.398^{* *}$ & 1 & $-0.197^{*}$ & -0.042 & $-0.201^{*}$ & $-0.179^{*}$ & $-0.191^{*}$ & $-0.225^{* *}$ \\
\hline
\end{tabular}

\footnotetext{
* Represent significance at the levels of 0.05 .
}

** Represent significance at the levels of 0.01 . 

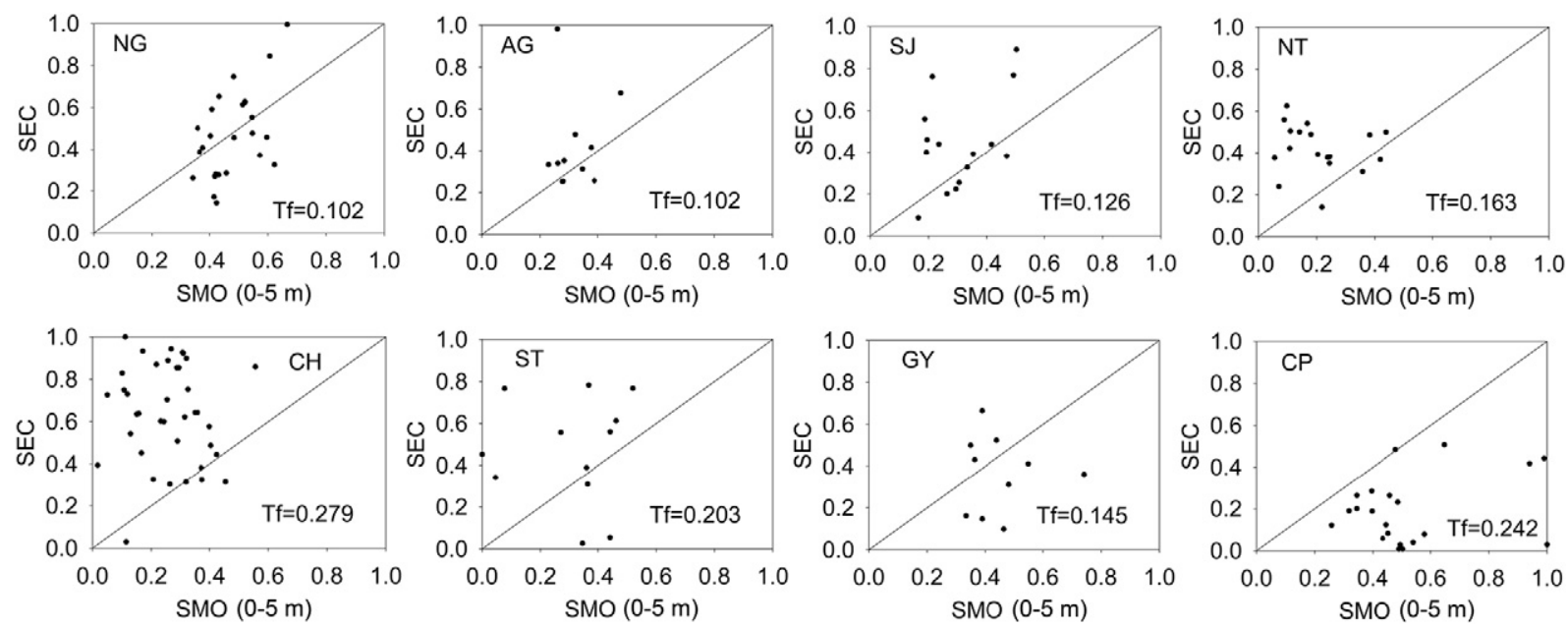

Fig. 5. Illustration of the trade-offs between SEC and SMO (0-5 m).

variables was inadequate. The dominant influencing variables (soil particle size, Alt, and $\mathrm{CH}$ ) were similar in the soil layers below $1 \mathrm{~m}$. As depth increased, the total explanatory capability of the environmental variables for the trade-offs was enhanced, and the influencing power of the various environmental variables changed. For instance, the influence of Alt and SloG began in the 2-5 m layers; $\mathrm{CP}$ only had a significant effect in the 0-3 m layers, which may have resulted from the shallow distribution of the roots. The influence of Sptop was only significant at 4-5 m, possibly because Sptop was relatively flat and favored the transfer of water to deeper soil layers. The environmental variables first influenced the two ESs and then influenced the relationship between them, but the internal mechanism was more complex. For example, as Vec and SloG increased, SEC was enhanced, and SMO decreased (Fig. 4). Finally, the SEC-SMO trade-off increased (Fig. 7). The relationship was clear, but the explanatory capabilities of each variable differed between the ESs and their trade-offs (Tables 2, 4 and 7).

Considering the redundancy analysis (RDA) and ES assessment results overall, vegetation type, Silt, Sand, and Alt were the dominant influencing factors on the SEC-SMO trade-offs, while SloG and slope position were second. Arranging NG, AG, SJ, and GY could decrease the extent of the trade-offs, and NG and AG had the most positive effects. The trade-off values on Spup were often lower, but those on Spdown were often higher. With higher SloG, Sand and Clay contents, the trade-offs became stronger, but with higher the Silt and Alt, the trade-offs were weaker. Additionally, strong interaction effects existed among the environmental variables. Based on the above results, manual regulation of trade-offs could be achieved by different combinations of vegetation types, slope position, SloG, and soil particle size composition. For example, NG, AG, and SJ were arranged on an upper hill slope (Spup) with higher Alt and lower SloG could lead to the lowest trade-off extent, but where trade-offs were severe (Spdow, $\mathrm{CP}$ and $\mathrm{CH}$ ), the ES conflicts could be reduced with soil improvement measures that increase Silt and decrease Sand and Clay. Moreover, because the ES trade-offs and their dominant influencing factors varied in different soil layers, the corresponding influencing factors for certain soil layers should be regulated in ES management.

\subsubsection{Redundancy analysis (RDA) of the CAS-SMO trade-off and environ- mental factors}

The cumulative percentage variance in the CAS-SMO trade-offs explained on the first two axes of the RDA was 48.09\%, and the overall test of the canonical relationship was significant (Table 8). As illustrated in Fig. 8, the arrow positions of the CAS-SMO trade-offs were similar to those of the SEC-SMO trade-offs, which also indicated the complexity and specificity of shallow soil moisture. The vegetation type (NG and $\mathrm{CP}$ ), Sand, and Clay were highly positively correlated with the first ordination axis, and Vec, vegetation type (NT and SJ), and SOM were highly negatively correlated.

The environmental variables listed in Table 9 significantly $(p<0.05)$ impacted the CAS-SMO trade-offs. The number of environmental
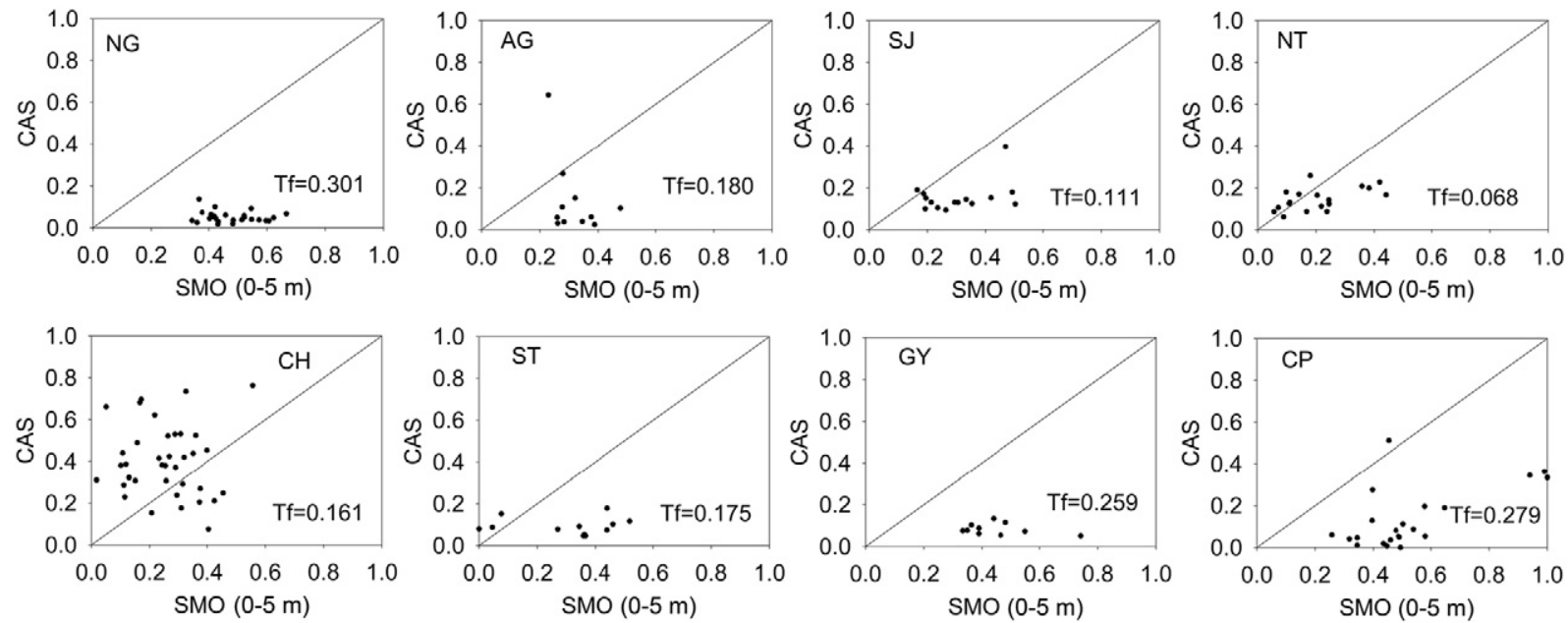

Fig. 6. Illustration of the trade-offs between CAS and SMO (0-5 m). 
Table 6

Eigenvalues and explained variance of the redundancy analysis axes for SEC-SMO tradeoffs.

\begin{tabular}{|c|c|c|c|c|}
\hline & Axis 1 & Axis 2 & Axis 3 & Axis 4 \\
\hline Eigenvalues & 0.3573 & 0.0195 & 0.0057 & 0.0026 \\
\hline Explained variation (cumulative, \%) & 35.73 & 37.68 & 38.24 & 38.51 \\
\hline Permutation test on all axes & $P=0.002$ & & & \\
\hline
\end{tabular}

variables with conditional effects was far less than that for marginal effects, indicating strong interaction effects among the environmental variables. For the entire soil layer $(0-5 \mathrm{~m})$, Vec and vegetation type were the dominant explanatory variables, and the remaining variables played a secondary role. Overall, the explanatory capability of the environmental variables for the CAS-SMO trade-offs was far higher than that for the SEC-SMO trade-offs.

The total explanatory capability of the environmental variables for the CAS-SMO trade-offs increased, decreased, and then increased again as depth increased (the total explanatory capability was $49.2 \%$, $59.4 \%, 42.1 \%, 34.1 \%$, and $38.8 \%$ from the $0-1 \mathrm{~m}$ to the $4-5 \mathrm{~m}$ depths, respectively), and the influencing power of the different environmental variables varied as depth increased. Regarding the conditional effects, the influence of $\mathrm{Vec}$ and vegetation type was always dominant, the influencing power of grass (NG and AG) and $\mathrm{CP}$ was relatively high in the $0-3 \mathrm{~m}$ soil layers, and that of $\mathrm{NT}$ and $\mathrm{CH}$ was relatively high in the 3-5 m soil layers, which was consistent with the plant root distribution and water consumption characteristics.

Vegetation is the main reason for the conflicts between CAS and SMO. The higher biomass implied higher carbon storage, but it also implied stronger transpiration. This influence is not significant in areas with abundant rainfall, where a balance of dense vegetation growth and water conservation can be achieved. However, in arid and semiarid areas, rainfall is insufficient, so plant growth comes at the cost of sustained soil water consumption, especially deep soil water. It is difficult to supply deep soil water through rainfall and groundwater, and a lack of deep soil water can cause reductions in vegetation biomass and stunted growth as well as vegetation die-off (Wang et al., 2004a; Wang et al., 2008). This phenomenon emerged in the Loess Plateau of China and seriously influenced the sustainability of vegetation recovery in this region.

\subsection{The complexity of ES relationships and scale dependence}

SEC, SMO, CAS were three important ESs in the study area. After implementing the GFGP, SEC increased as CAS increased, but vegetation with high biomass usually decreased SMO and caused soil desiccation

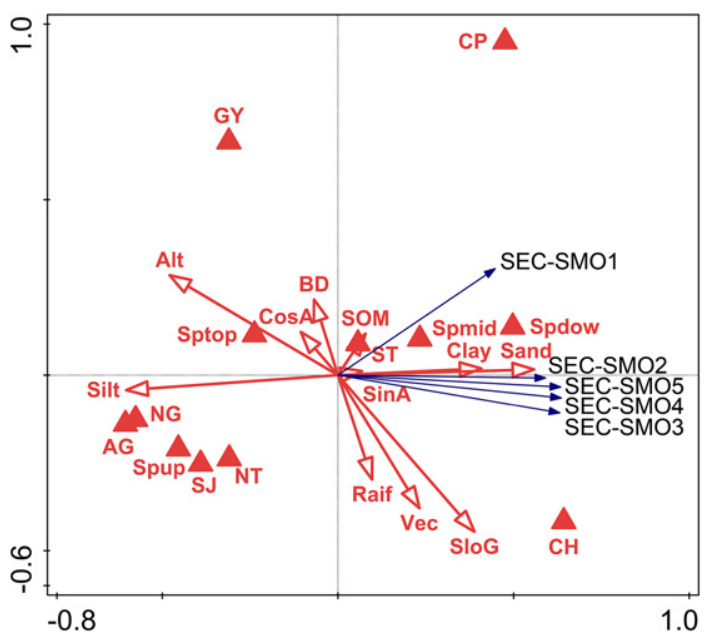

Fig. 7. Biplot diagram of the RDA between SEC-SMO trade-offs and environmental factors.
(Yang et al., 2015). Sustained soil desiccation can induce stunted vegetation growth and die-off (Wang et al., 2004a; Wang et al., 2008), negating the gains in SEC and CAS, so the relationship among the three ESs is particularly important in the study area.

In this study, the different ESs depended on different time scales. Shallow SMO was impacted by rainfall events and fluctuated greatly with time (Yang et al., 2014b; Fang et al., 2016), and deep SMO was relatively stable and determined by long-term soil water consumption and provision (Yang et al., 2014b; Fang et al., 2016). Vegetation types influenced the deep SMO and the formation of dried soil layer (DSL). For example, Wang et al. (2010) found that DSLs formed after 2 years of Medicago sativa growth and 3 years of Caragana korshinskii growth. After 4 years of growth, DSLs under Medicago sativa were thicker, but after 31 years, they became thicker under $C$. korshinskii. Carbon storage by the vegetation increased nonlinearly with growing stages (Shi et al., 2012). Soil erosion exhibited heterogeneous changes over a certain period, and soil losses caused by extreme rainfall events accounted for nearly all soil losses (Estrany et al., 2010; Feng et al., 2015).

The ESs also exhibited spatial variability. The SMO in the study area varied vertically; for example, Fang et al. (2016) divided the deep soil moisture into three layers in the Ansai watershed: (i) a rainfall transpiration layer $(80-220 \mathrm{~cm})$, (ii) a transition layer $(220-400 \mathrm{~cm})$, and (iii) a stable layer $(400-500 \mathrm{~cm})$. The results of this study also indicated that ES trade-offs changed with depth; for example, the positions of the arrows indicating ES trade-offs in the shallow soil layer $(0-1 \mathrm{~m})$ were different from those in the deep soil layer (2-5 m) (Figs. 6 and 7). The relationships among the ESs also exhibited horizontal spatial heterogeneity; for instance, the relationship between SMO and SEC for $\mathrm{CH}$ varied greatly as the scatter points of the ES pairs of 38 sample plots covered half of the figure (Fig. 4). Overall, $\mathrm{CH}$ benefited SEC, but there were still three sample plots in which $\mathrm{CH}$ benefited SMO (Fig. 4). Furthermore, it is generally agreed that water consumption by evapotranspiration has a negative effect on water yield, but vegetation evapotranspiration increases air humidity and boosts the occurrence of rainfall at larger spatial scales (Ellison et al., 2012). In the Ansai watershed, the vegetation coverage was high in the southeast and low in the northwest (Su et al., 2012b), which caused spatial heterogeneity in CAS and SEC.

Individual ESs often depend on multiple ecological processes, and one ecological process can affect different ESs (Howe et al., 2014). For example, CAS was controlled by various ecological processes, such as physiological processes, soil erosion, and the water cycle, and soil erosion process influenced multiple ESs, such as carbon sequestration, grain production, and water purification.

In summary, the ESs depended on temporal and spatial scales, and the corresponding ecological processes interacted with each other. Therefore, the relationships among ESs were complex, so coordinating them remains a challenge.

3.4. The difference between the effects of environmental factors on ESS and those on ES trade-offs

Three ESs and their trade-offs were influenced by many environmental factors. Generally, vegetation was directly related to carbon sequestration, water consumption and conservation, and soil erosion control (Fu et al., 2011; Feng et al., 2012; Lü et al., 2012; Feng X.M. et al., 2016; Fang et al., 2016; Li et al., 2016). Landforms influenced the translocation of soil particles and water and were closely related to soil erosion and soil moisture (Kateb et al., 2013; Feng Q. et al., 2016). Meteorological factors, such as rainfall and solar radiation, influenced soil water recharge and evaporation (Western and Blöschl, 1999; Zhang et al., 2016) and induced soil erosion (Feng et al., 2015). Soil properties were related to soil water and nutrient conservation (Wang et al., 2011; Feng Q. et al., 2016) and thus influenced the three ESs. The dominant factors influencing ESs changed with spatial location, but those for ES trade-offs changed in a more complicated way. 
Table 7

Marginal (MarE) and conditional effects (ConE) from the summary of forward selection for SEC-SMO trade-offs.

\begin{tabular}{|c|c|c|c|c|c|c|c|c|c|c|c|c|}
\hline \multirow[t]{2}{*}{ Variables } & \multicolumn{2}{|c|}{$0-5 \mathrm{~m}$} & \multicolumn{2}{|l|}{$0-1 \mathrm{~m}$} & \multicolumn{2}{|l|}{$1-2 \mathrm{~m}$} & \multicolumn{2}{|c|}{$2-3 \mathrm{~m}$} & \multicolumn{2}{|c|}{$3-4 m$} & \multicolumn{2}{|l|}{$4-5 m$} \\
\hline & MarE & ConE & MarE & ConE & MarE & ConE & MarE & ConE & MarE & ConE & MarE & ConE \\
\hline Silt & 14.5 & 14.5 & 7.8 & 6.2 & 10.7 & 10.7 & 11.7 & - & 16.7 & 16.7 & 17.3 & 17.3 \\
\hline $\mathrm{CH}$ & 12.6 & - & - & - & 10 & - & 15.7 & 15.7 & 10.9 & - & 12.4 & - \\
\hline Sand & 12.4 & - & 6.3 & - & 9.3 & - & 9.6 & - & 15.3 & - & 14.7 & - \\
\hline Alt & 10.3 & - & - & - & 7.7 & - & 9.6 & - & 10.5 & - & 12.1 & - \\
\hline Spup & 9.5 & 7.9 & 8.3 & 4.6 & 8.6 & 7.3 & 8.8 & 9.1 & 9.3 & 7.6 & 6.6 & 5.2 \\
\hline SloG & 8.1 & 7.4 & - & - & 6.1 & 5.9 & 8 & 3.5 & 7.3 & 6.3 & 7.2 & 5.6 \\
\hline Clay & 6.4 & - & 3.5 & - & 3.9 & - & 5.1 & - & 9 & - & 8.3 & - \\
\hline NG & 6 & 3.9 & 3.2 & - & 7.2 & 5.1 & 4.2 & - & 4.1 & 2.9 & 5.2 & 4 \\
\hline Spdow & 5.2 & - & 4.2 & - & 5.3 & - & 5.5 & - & 6.2 & - & 4.6 & - \\
\hline Vec & 3 & - & - & - & - & - & 3.4 & - & - & - & 2.9 & - \\
\hline Spmid & 2.7 & - & - & - & - & - & - & - & - & - & - & - \\
\hline AG & 2.7 & - & - & - & - & - & - & - & 2.9 & - & 2.9 & - \\
\hline GY & - & 3.4 & - & - & - & - & - & - & - & 2.7 & - & 4.2 \\
\hline $\mathrm{CP}$ & - & - & 8.5 & 8.5 & 2.9 & 2.3 & - & 4.5 & - & - & - & - \\
\hline Sptop & - & - & - & - & - & - & - & - & - & - & - & 1.5 \\
\hline
\end{tabular}

"-" Indicates that the marginal or conditional effect is not significant.

Therefore, it is necessary to combine ESs, ES trade-offs, and their influencing factors for ES management, which would also provide a new way to understand the complexity of ES relationships.

As illustrated in Tables 2, 4 and 7, the first three important influencing factors with marginal effects on SEC were SloG, vegetation type (CP), and Vec; for SMO (0-5 m), they were Vec, vegetation type (CP), and Sand; and for SEC-SMO, they were Silt, vegetation type $(\mathrm{CH})$, and Sand. Therefore, the order of importance of the influencing factors for the SEC-SMO trade-offs differed from that for single ESs. The effect of Silt on the SEC-SMO trade-off was highest, but it was ranked ninth for SMO alone and did not significantly affect SEC. The slope position significantly affected the SEC-SMO trade-offs but not the two ESs. The effects of the environmental factors on ES trade-offs were based on single ESs, but due to the complexity of the relationships among ESs and the interaction effects among environmental variables (Rodriguez et al., 2006), the order of influence of the variables on the trade-offs varied greatly. The intrinsic mechanism requires further study.

The differences in conditional effects between ESs and ES trade-offs were similar to those in the marginal effects, so we do not elaborate further here.

As illustrated in Tables 3, 4 and 9, CAS, SMO, and their trade-offs were mainly influenced by Vec and vegetation types. Except for CosA and SJ, the factors that had significant effects on the CAS-SMO tradeoffs also had significant effects on one or two ESs, indicating that the complexity of the relationship between CAS and SMO was low. Vegetation was pivotal for ES trade-offs because carbon storage accumulation and soil water consumption increased simultaneously as the vegetation grew.

\subsection{Recommendations for ES regulation based on ES trade-offs}

SMO was the core of the relationships among the three ESs, and the relationship between SMO and the other ESs requires more attention. Therefore, in addition to the effects of environmental factors on ESs, we must also consider the SMO-CAS and SMO-SEC trade-offs and their influencing factors on ES management practices, and the corresponding

Table 8

Eigenvalues and explained variance of the redundancy analysis axes for the CAS-SMO trade-off.

\begin{tabular}{lllll}
\hline & Axis 1 & Axis 2 & Axis 3 & Axis 4 \\
\hline Eigenvalues & 0.4525 & 0.0284 & 0.0261 & 0.0065 \\
Explained variation (cumulative, \%) & 45.25 & 48.09 & 50.70 & 51.35 \\
Permutation test on all axes & $P=0.002$ & & & \\
\hline
\end{tabular}

recommendations are as follows (these recommendations apply only to the Ansai watershed and the analogous region in the Loess Plateau).

In summary, the selection of vegetation types was the most important element for ecological restoration. SJ was suitable for growth in the study area, and the three ESs were relatively coordinated. Thus, SJ was an appropriate afforestation plant for the Ansai watershed. Moreover, we had to consider slope position and slope gradient to arrange the vegetation types; for example, we could arrange SJ on the upper hill slope at a higher altitude and at a lower slope gradient; the trade-off between SEC and SMO was the lowest, and the trade-off between CAS and SMO was also acceptable. A lower altitude position or gully bottom usually had higher soil moisture content (Feng et al., 2013), so we could plant trees and shrubs at a reasonable density to achieve higher SEC and CAS. GY and CP had higher economic benefits, but attention must be paid to soil erosion. Planting NG in a place with poor soil moisture conditions was conducive to sustainable vegetation recovery. Furthermore, manual management and improvement measures were also important for coordinating the ES relationships. These measures include building bench terraces to change the topographical conditions and implementing artificial rainwater collection measures to fully utilize water resources (Wei et al., 2016), improving soil properties to increase organic matter and silt content (with greater emphasis on organic fertilizer) (Ankenbauer and Loheide, 2017; Geng et al., 2017), covering the soil surface (e.g., straw mulching) to decrease water evaporation and control soil erosion (Fernández and Vega, 2016), applying chemical measures such as water-retaining agents (Yin et al., 2016) and transpiration-controlling preparation (Li et al., 2015) to decrease water consumption, and finally, employing environmentally friendly tillage methods, such as reduced/ no-tillage, straw retention, crop rotation, forest-crop intercropping, and mix-sowing of shrubs and grass (Fang et al., 2016).

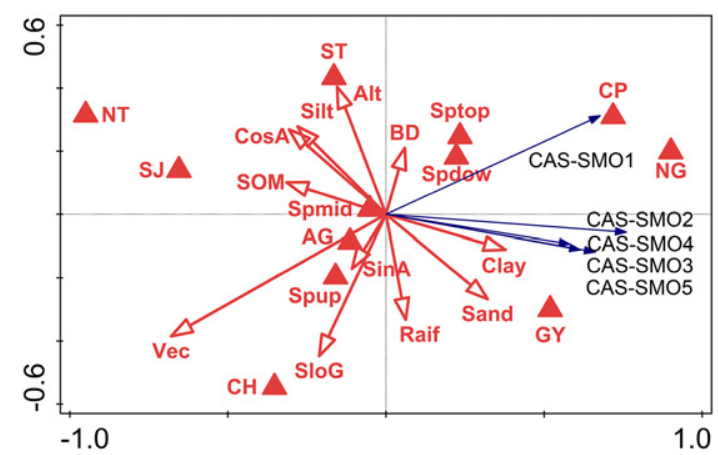

Fig. 8. Biplot diagram of the RDA between CAS-SMO trade-offs and environmental factors 
Table 9

Marginal (MarE) and conditional effects (ConE) from the summary of forward selection for the CAS-SMO trade-offs.

\begin{tabular}{|c|c|c|c|c|c|c|c|c|c|c|c|c|}
\hline \multirow[t]{2}{*}{ Variables } & \multicolumn{2}{|l|}{$0-5 \mathrm{~m}$} & \multicolumn{2}{|l|}{$0-1 \mathrm{~m}$} & \multicolumn{2}{|l|}{$1-2 \mathrm{~m}$} & \multicolumn{2}{|c|}{$2-3 \mathrm{~m}$} & \multicolumn{2}{|c|}{$3-4 \mathrm{~m}$} & \multicolumn{2}{|c|}{$4-5 \mathrm{~m}$} \\
\hline & MarE & ConE & MarE & ConE & MarE & ConE & MarE & ConE & MarE & ConE & MarE & ConE \\
\hline Vec & 20.9 & 20.9 & 33.5 & 33.5 & 25.6 & 25.6 & 13.9 & $=$ & 12.3 & 12.3 & 16.2 & 16.2 \\
\hline NG & 16.1 & 6.8 & 18.5 & 4.8 & 16.9 & 6.5 & 15.3 & 15.3 & 9.5 & 1.8 & 11.7 & 2.8 \\
\hline NT & 15.6 & 4.3 & 7.8 & 1.4 & 17.7 & 3.6 & 8.2 & 1.8 & 7.3 & 5.2 & 14 & 6.6 \\
\hline Clay & 8.9 & - & 4.7 & 3.2 & 10.3 & - & 11.3 & 8.3 & 3.6 & - & - & - \\
\hline $\mathrm{CP}$ & 8.8 & 2.9 & 11 & 4.4 & 13.1 & 5.1 & 6 & 10.5 & 4 & - & 4 & - \\
\hline Sand & 7.1 & 9.7 & - & - & 8.4 & - & 7.5 & - & 3.3 & 4.7 & 2.9 & 4.7 \\
\hline $\operatorname{Cos} \mathrm{A}$ & 7.1 & - & - & - & 6.8 & - & 5.9 & - & 3.9 & - & 3.9 & - \\
\hline Silt & 5.8 & - & - & - & 8.1 & 12.6 & 6.8 & - & - & - & - & - \\
\hline SOM & 5.7 & - & 3.4 & - & 5.3 & - & 3.8 & - & 3.3 & - & 7 & - \\
\hline SJ & 5.5 & - & 3 & - & 10.5 & - & 7.1 & - & - & - & - & - \\
\hline $\mathrm{CH}$ & 2.7 & - & 13.3 & 1.9 & - & - & - & - & 7.5 & 4.1 & 5.5 & 4.1 \\
\hline Alt & - & 2.9 & - & - & 2.9 & 3.6 & 4.1 & 3.6 & - & 3.2 & - & 2.3 \\
\hline GY & - & 2.3 & - & - & - & 2.4 & - & 2.6 & 3.5 & - & 3 & - \\
\hline SloG & - & - & 8.2 & - & - & - & - & - & - & - & - & - \\
\hline Spup & - & - & 3.1 & - & - & - & - & - & - & - & - & - \\
\hline Spdow & - & - & - & - & 2.6 & - & - & - & - & - & - & - \\
\hline BD & - & - & - & - & - & - & - & - & - & 2.8 & - & - \\
\hline ST & - & - & - & - & - & - & - & - & - & - & - & 2.1 \\
\hline
\end{tabular}

“-” Indicates that the marginal or conditional effect is not significant.

Following the above recommendations for ES regulation will enhance the well-being of local residents because improving the ecological environment (ecological benefit) can increase economic and social benefits. For example, Hippophae rhamnoides was the most appropriate afforestation plant for coordinating the three ESs, but it also has economic benefits. The plant has a high vitamin C content, and it can be used to produce fruit juice. Several brands of Hippophae rhamnoides juice are enjoyed by consumers.

\subsection{The significance of this study in mitigating non-point source pollution}

Non-point source pollution is mainly caused by nitrogen and phosphorus fertilizers, pesticides and other organic or inorganic nutrients that are leached from field surface runoff or agricultural wastewater discharge. Soil and water loss is an important reason for the non-point source pollution in the Loess Plateau of China (Wu et al., 2015); special water and soil processes ("soil and water flow together") in this region that lead to the loss of nitrogen and phosphorus differ greatly from those of other areas of China. The loss of soil nitrogen and phosphorus is mainly caused by soil loss, as the nitrogen and phosphorus contents in runoff are very low (Wu and Ma, 2015). Therefore, enhancing SEC means mitigating non-point source pollution in the study area. The loss of nutrient contents from the sediment under various vegetation types can be measured by a runoff plot experiment, and although these data are not provided in this study, the proposed recommendations (Section 3.5 , such as the combination of vegetation type, slope gradient, slope position and altitude) can control non-point source pollution. Finally, we can coordinate the relationship among the four ESs (non-point source pollution control, SEC, CAS, and SMO).

\section{Conclusions}

The general trend in SEC for various vegetation types was $\mathrm{CH}>\mathrm{NG}$ $>\mathrm{ST}>\mathrm{SJ}>\mathrm{AG}>\mathrm{NT}>\mathrm{GY}>\mathrm{CP}$; that in $\mathrm{CAS}$ was $\mathrm{CH}>\mathrm{SJ}>\mathrm{NT}>\mathrm{AG}>\mathrm{CP}$ $>\mathrm{ST}>\mathrm{GY}>\mathrm{NG}$; and that in $\mathrm{SMO}$ was $\mathrm{CP}>\mathrm{NG}>\mathrm{GY}>\mathrm{AG}>\mathrm{SJ}>\mathrm{ST}$ $>\mathrm{CH}>\mathrm{NT}$. Synergies were identified between SEC and CAS as well as the trade-offs between these two ESs and SMO.

Vegetation type, altitude, and silt and sand composition had a dominant influence on SEC-SMO trade-offs with slope gradient and slope position being secondary. Arranging NG, AG, and SJ could decrease the extent of trade-offs. The effects of environmental factors on CAS-SMO trade-offs were not complex; vegetation coverage and types were the dominant factors. The extent of the CAS-SMO trade-offs for NT was the lowest, and that for SJ was the second lowest. NT was not an appropriate afforestation plant due to its high water consumption.

Considering the overall relationships among the three ESs, SJ was the most appropriate afforestation plant. Interaction effects existed among the environmental variables, and trade-offs and their dominant influencing factors varied among different soil layers. Therefore, to control trade-offs, we must consider the corresponding influencing factors. Different combinations of vegetation types, slope positions, slope gradients, and soil properties could help regulate the ES relationships, and manual management and soil improvement measures are also important.

\section{Author contributions}

Qiang Feng performed the experimental work and prepared the manuscript. Wenwu Zhao and Bojie Fu designed the field experiment and reviewed the manuscript. Jingyi Ding performed the experimental work and data collection. Shuai Wang revised the manuscript.

\section{Conflicts of interest}

The authors declare no conflict of interest.

\section{Acknowledgments}

This research was supported by the National Natural Science Foundation of China (Nos. 41230745, 41501201) and State Key Laboratory of Earth Surface Processes and Resource Ecology (No.2017-FX-01(2)).

\section{Appendix A. Supplementary data}

Supplementary data to this article can be found online at http://dx. doi.org/10.1016/j.scitotenv.2017.07.079.

\section{References}

Ankenbauer, K.J., Loheide, S.P., 2017. The effects of soil organic matter on soil water retention and plant water use in a meadow of the Sierra Nevada, CA. Hydrol. Processes. 31, 891-901.

Asbjornsen, H., Goldsmith, G.R., Avarado-Barrientos, M.S., Rebel, K., Van Osch, F.P., Rietkerk, M., Chen, J., Gotsch, S., Tobon, C., Geissert, D.R., Gomez-Tagle, A., Vache, K., Dawson, T.E., 2011. Ecohydrological advances and applications in plant water relations research: a review. J. Plant Ecol. 4, 3-22.

Ballantine, K.A., Lehmann, J., Schneider, R.L., 2015. Trade-offs between soil-based functions in wetlands restored with soil amendments of differing lability. Ecol. Appl. 25, 215-225. 
Bennett, E.M., Peterson, G.D., Gordon, L.J., 2009. Understanding relationships among multiple ecosystem services. Ecol. Lett. 12, 1394-1404.

Bradford, J.B., D'Amato, A.W., 2012. Recognizing trade-offs in multi-objective land management. Front. Ecol. Environ. 10, 210-216.

Chen, H.S., Shao, M.A., Li, Y.Y., 2008. Soil desiccation in the Loess Plateau of China. Geoderma 143, 91-100.

Chen, L.D., Wang, J.P., Wei, W., Fu, B.J., Wu, D.P., 2010. Effects of landscape restoration on soil water storage and water use in the Loess Plateau region, China. For. Ecol. Manag. 259, 1291-1298.

Costanza, R., d'Arge, R., de Groot, R., Farber, S., Grasso, M., Hannon, B., Limburg, K., Naeem, S., O'Neill, R.V., Paruele, J., Raskin, R.G., Sutton, P., Van den Belt, M., 1997. The value of the world's ecosystem services and natural capital. Nature 387, 253-260.

Daily, G.C., 1997. Nature's Services: Societal Dependence on Natural Ecosystems. Island Press, Washington, DC.

Darvill, R., Lindo, Z., 2016. The inclusion of stakeholders and cultural ecosystem services in land management trade-off decisions using an ecosystem services approach. Landsc. Ecol. 31, 533-545.

Ellison, D., Futter, M.N., Bishop, K., 2012. On the forest cover-water yield debate: from demand-to supply-side thinking. Glob. Chang. Biol. 18, 806-820.

Estrany, J., Garcia, C., Batalla, R.J., 2010. Hydrological response of a small Mediterranean agricultural catchment. J. Hydrol. 380, 180-190.

Fang, X.N., Zhao, W.W., Wang, L.X., Feng, Q., Ding, J.Y., Liu, Y.X., Zhang, X., 2016. Variations of deep soil moisture under different vegetation types and influencing factors in a watershed of the Loess Plateau, China. Hydrol. Earth Syst. Sci. 20, 3309-3323.

Feng, X.M., Fu, B.J., Lü, N., Zeng, Y., Wu, B.F., 2012. How ecological restoration alters ecosystem services: an analysis of carbon sequestration in China's Loess Plateau. Sci Rep 3, 2846.

Feng, Q., Zhao, W.W., Qiu, Y., Zhao, M.Y., Zhong, L.N., 2013. Spatial heterogeneity of soil moisture and the scale variability of its influencing factors: a case study in the loess plateau of china. Water 5, 1226-1242.

Feng, Q., Guo, X.D., Zhao, W.W., Qiu, Y., Zhang, X., 2015. A comparative analysis of runoff and soil loss characteristics between "extreme precipitation year" and "normal precipitation year" at the plot scale: a case study in the Loess Plateau in China. Water 7, 3343-3366.

Feng, X.M., Fu, B.J., Piao, S.L., Wang, S., Ciais, P., Zeng, Z.Z., Lu, Y.H., Zeng, Y., Li, Y., Jiang, X.H., Wu, B.F., 2016. Revegetation in China's Loess Plateau is approaching sustainable water resource limits. Nat. Clim. Chang. 6. http://dx.doi.org/10.1038/NCLIMATE3092.

Feng, Q., Zhao, W.W., Wang, J., Zhang, X., Zhao, M.Y., Zhong, L.N., Liu, Y.X., Fang, X.N., 2016. Effects of different land-use types on soil erosion under natural rainfall in the Loess Plateau, China. Pedosphere. 26, 243-256.

Fernández, C., Vega, J.A., 2016. Are erosion barriers and straw mulching effective for controlling soil erosion after a high severity wildfire in NW Spain? Ecol. Eng. 87, 132-138.

Foster, G.R., Meyer, L.D., Onstad, C.A., 1977. A runoff erosivity factor and variable slope length exponents for soil loss estimates. Trans. ASAE. 20, 683-687.

Frank, S., Fürst, C., Witt, A., 2014. Making use of the ecosystem services concept in regional planning-trade-offs from reducing water erosion. Landsc. Ecol. 29, 1377-1391.

Fu, B.J., Liu, Y., Lü, Y.H., He, C.S., Zeng, Y., Wu, B.F., 2011. Assessing the soil erosion control service of ecosystems change in the Loess Plateau of China. Ecol. Complex. 8, 284-293.

Geng, R., Zhang, G.H., Ma, Q.H., Wang, L.J., 2017. Soil resistance to runoff on steep croplands in Eastern China. Catena 152, 18-28.

Gissi, E., Gaglio, M., Reho, M., 2016. Sustainable energy potential from biomass through ecosystem services trade-off analysis: the case of the province of Rovigo (northern Italy). Ecosyst. Services. 18, 1-19.

Goldstein, J.H., Caldarone, G., Duarte, T.K., Ennaanay, D., Hannahs, N., Mendoza, G., Polasky, S., Wolny, S., Daily, G.C., 2012. Integrating ecosystem-service tradeoffs into land-use decisions. PNAS 109, 7565-7570.

Haase, D., Schwarz, N., Strohbach, M., Kroll, F., Seppelt, R., 2012. Synergies, trade-offs, and losses of ecosystem services in urban regions: an integrated multiscale framework applied to the Leipzig-Halle region, Germany. Ecol. Soc. 17, 22.

Hou, J., Fu, B.J., Liu, Y., Lü, N., Gao, G.Y., Zhou, J., 2014. Ecological and hydrological response of farmlands abandoned for different lengths of time: evidence from the loess hill slope of China. Glob. Planet. Chang. 113, 59-67.

Howe, C., Suich, H., Vira, B., Mace, G.M., 2014. Creating win-wins from trade-offs? Ecosystem services for human well-being: a meta-analysis of ecosystem service trade-offs and synergies in the real world. Glob. Environ. Chang. 28, 263-275.

Jia, X.Q., Fu, B.J., Feng, X.M., Hou, G.H., Liu, Y., Wang, X.F., 2014. The tradeoff and synergy between ecosystem services in the grain-for-green areas in northern Shaanxi, China. Ecol. Indic. 43, 103-113.

Kateb, H.E., Zhang, H., Zhang, P., Mosandl, R., 2013. Soil erosion and surface runoff on different vegetation covers and slope gradients: a field experiment in southern Shaanxi Province, China. Catena. 105, 1-10.

Lautenbach, S., Volk, M., Strauch, M., 2013. Optimization-based trade-off analysis of biodiesel crop production for managing an agricultural catchment. Environ. Model. Softw. 48, 98-112.

Li, Y.S., Huang, M.B., 2008. Pasture yield and soil water depletion of continuous growing alfalfa in the Loess Plateau of China. Agric. Ecosyst. Environ. 124, 24-32.

Li, M., Jia, L., Yu, D., Ma, L., Jia, Z., 2015. Research on applying new materials for Pinus tabuliformis plantations in barren sites of plain in Beijing. J. Beijing For. Univ. 37, 64-73 (in Chinese).

Li, S., Liang, W., Fu, B.J., Lü, Y.H., Fu, S.Y., Wang, S., Su, H.M., 2016. Vegetation changes in recent large-scale ecological restoration projects and subsequent impact on water resources in China's Loess Plateau. Sci. Total Environ. 569-570, 1032-1039.

Liu, B.Y., Nearing, M.A., Risse, L.M., 1994. Slope gradient effects on soil loss for steep slopes. Trans. ASAE. 37, 1835-1840.
Liu, Y.C., Wang, Q.F., Yu, G.R., Zhu, X.J., Zhan, X.Y., Guo, Q., Yang, H., Li, S.G., Hu, Z.M., 2011. Ecosystems carbon storage and carbon sequestration potential of two main tree species for the Grain for Green Project on China's hilly Loess Plateau. Acta Ecol. Sin. 31, 4277-4286 (in Chinese)

Liu, Y.X., Zhao, W.W., Wang, L.X., Zhang, X., Daryanto, S., Fang, X.N., 2016. Spatial variations of soil moisture under Caragana Korshinskii kom. From different precipitation zones: field based analysis in the Loess Plateau, China. Forests 7 (31).

Lü, Y.H., Fu, B.J., Chen, L.D., Liu, G.H., Wei, W., 2007. Nutrient transport associated with water erosion: progress and prospect. Prog. Phys. Geogr. 31, 607-620.

Lü, Y.H., Fu, B.J., Feng, X.M., Zeng, Y., Liu, Y., Chang, R.Y., Sun, Ge, Wu, B.F., 2012. A policydriven large scale ecological restoration: quantifying ecosystem services changes in the Loess Plateau of China. PLoS One 7, e31782.

Lü, N., Fu, B.J., Jin, T.T., Chang, R.Y., 2014. Trade-off analyses of multiple ecosystem services by plantations along a precipitation gradient across Loess Plateau landscapes. Landsc. Ecol. 29, 1697-1708.

MA (Millennium Ecosystem Assessment), 2005. Ecosystems and Human Well-Being: Synthesis. Island Press, Washington D.C.

Ma, Q.Y., Chen, X.L., Wang, J., Lin, C., Kang, F.F., Cao, W.Q., Ma, Z.B., Li, W.Y., 2002. Carbon content rate in constructive species of main forest types in northern China. J. Beijing For. Univ. 24, 96-100 (in Chinese).

Mach, M.E., Martone, R.G., Chan, K.M.A., 2015. Human impacts and ecosystem services insufficient research for trade-off evaluation. Ecosyst. Serv. 16, 112-120.

McCool, D.K., Brown, L.C., Foster, G.R., Mutchler, C.K., Meyer, L.D., 1987. Revised slope steepness factor for the Universal Soil Loss Equation. Trans. ASAE 30 1387-1396.

McCool, D.K., Foster, G.R., Mutchler, C.K., Meyer, L.D., 1989. Revised slope length factor for the universal soil loss equation. Trans. ASAE 32, 1571-1576.

Nelson, D.M., Sommer, L.E., 1975. A rapid and accurate method for estimating organic carbon in soil. Proc. Indiana Acad. Sci. 84, 456-462.

Nunes, A.N., De Almeida, A.C., Coelho, C.O., 2011. Impacts of land use and cover type on runoff and soil erosion in a marginal area of Portugal. Appl. Geogr. 31, 687-699.

Pu, J.Y., Yao, X.Y., Den, Z.Y., Zhang, C.J., Zhang, M.C., Wang, W.T., 2006. Impact of climate change on soil water content in Loess Plateau, Gansu. Chin. J. Soil Sci. 37, 1086-1090 (in Chinese).

Raudsepp-Hearne, C., Peterson, G.D., Bennett, E.M., 2010. Ecosystem service bundles for analyzing tradeoffs in diverse landscapes. Proc. Natl. Acad. Sci. 107, 5242.

Renard, K.G., Foster, G.R., Weesies, G.A., McCool, D.K., Yoder, D.C., 1997. Predicting Soil Erosion by Water: A Guide to Conservation Planning with the Revised Universal Soil Loss Equation (RUSLE). USDA, Agricultural Handbook Number 703U.S. Government Printing Office, Washington, D.C.

Rodriguez, J.P., Beard Jr., T.D., Bennett, E.M., Cumming, G.S., Cork, S.J., Agard, J., Dobson, A.P., Peterson, G.D., 2006. Trade-offs across space, time, and ecosystem services. Ecol. Soc. 11, 28

Shen, J.P., Zhang, W.H., 2014. Characteristics of carbon storage and sequestration of Robinia Pseudoacacia forest land converted by farmland in the Hilly Loess Plateau Region. Acta Ecol. Sin. 34, 2746-2754.

Shi, S., Zhao, P., Zhou, M., Yang, X., 2012. Biomass and carbon storage of the secondary forest (Populus davidiana) at different stand growing stages in southern Daxinganling temperature zone. Proc. Natl. Acad. Sci. 21, 428-433 (in Chinese).

Su, C.H., Fu, B.J., He, C.S., Lü, Y.H., 2012a. Variation of ecosystem services and human activities: a case study in the Yanhe watershed of China. Acta Oecol. 44, 46-57.

Su, C.H., Fu, B.J., Wei, Y.P., Lü, Y.H., Liu, G.H., Wang, D.L., Mao, K.B., Feng, X.M., 2012b. Ecosystem management based on ecosystem services and human activities: a case study in the Yanhe watershed. Sustain. Sci. 7, 17-32.

Upadhyay, T.P., Solberg, B., Sankhayan, P.L., Shahi, C., 2013. Land-use changes, forest/soil conditions and carbon sequestration dynamics: a bio-economic model at watershed level in Nepal. J. Bioecon. 15, 135-170.

Vogdrup-Schmidt, M., Strange, N., Olsen, S.B., Thorsen, B.J., 2017. Trade-off analysis of ecosystem service provision in nature networks. Ecosyst. Serv. 23, 165-173.

Wang, L., Shao, M.A., Li, Y., 2004a. Study on relationship between growth of artificial Robinia pseudoacacia plantation and soil desiccation in the Loess Plateau of northern Shannxi Province. Sci. Silvae Sin. 40, 84-91 (in Chinese).

Wang, L., Shao, M.A., Zhang, Q.F., 2004b. Distribution and characters of soil dry layer in north Shaanxi Loess Plateau. 15 pp. 436-442.

Wang, L., Wang, Q.J., Wei, S.P., Shao, M.A., Li, Y., 2008. Soil desiccation for Loess soils on natural and regrown areas. For. Ecol. Manag. 255, 2467-2477.

Wang, Y.Q., Shao, M.A., Shao, H.B., 2010. A preliminary investigation of the dynamic characteristics of dried soil layers on the Loess Plateau of China. J. Hydrol. 381, 9-17.

Wang, Y.Q., Shao, M.A., Zhu, Y.J., Liu, Z.P., 2011. Impacts of land use and plant characteristics on dried soil layers in different climatic regions on the Loess Plateau of China. Agric. For. Meteorol. 151, 437-448.

Wang, F., Chen, A., Peng, Y., Xie, X., Yin, C., Wang, W., 2013. Effects of red soil slope field under different land-use patterns on surface runoff and soil erosion. J. Soil Wate Conserv. 27, 22-26 (in Chinese).

Wang, Y.Q., Shao, M.A., Liu, Z.P., 2013. Vertical distribution and influencing factors of soil water content within 21-m profile on the Chinese Loess Plateau. Geoderma 193-194, 300-310.

Wang, J.T., Peng, J., Zhao, M.Y., Liu, Y.X., Chen, Y.Q., 2017. Significant trade-off for the impact of Grain-for-Green Programme on ecosystem services in North-western Yunnan, China. Sci. Total Environ. 574, 57-64.

Wei, W., Chen, D., Wang, L.X., Daryanto, S., Chen, L.D., Yu, Y., Lu, Y.L., Sun, G., Feng, T.J., 2016. Global synthesis of the classifications, distributions, benefits and issues of terracing. Earth Sci. Rev. 159, 388-403.

Western, A.W., Blöschl, G., 1999. On the spatial scaling of soil moisture. J. Hydrol. 217, 203-224. 
White, C., Halpern, B.S., Kappel, C.V., 2012. Ecosystem service tradeoff analysis reveals the value of marine spatial planning for multiple ocean uses. Proc. Natl. Acad. Sci. 109, 4696-4701.

Williams, J.R., Jones, C.A., Dyke, P.T., 1984. A modeling approach to determining the relationship between erosion and productivity. Trans. ASAE. 27, 129-144.

Wischmeier, W.H., Smith, D.D., 1978. Predicting rainfall erosion losses. A guide to conservation planning. USDA, Agriculture Handbook 537. U.S. Government Printing Office, Washington D.C.

Wu, L., Ma, X., 2015. Research progress in erosion-type nonpoint source pollution process simulation of the Loess Plateau, China. Sciencepaper 10, 1497-1506 (in Chinese).

Wu, L., Gao, J., Ma, X., Li, D., 2015. Application of modified export coefficient method on the load estimation of non-point source nitrogen and phosphorus pollution of soil and water loss in semiarid regions. Environ. Sci. Pollut. Res. Int. 22, 10647-10660 (in Chinese).

Yang, L., Wei, W., Chen, L.D., Mo, B., 2012. Response of deep soil moisture to land use and afforestation in the semi-arid Loess Plateau, China. J. Hydrol. 475, 111-122.

Yang, L., Chen, L.D., Wei, W., Yu, Y., Zhang, H.D., 2014a. Comparison of deep soil moisture in two re-vegetation watersheds in semi-arid regions. J. Hydrol. 513, 314-321.
Yang, L., Wei, W., Chen, L.D., Chen, W.L., Wang, J.L., 2014b. Response of temporal variation of soil moisture to vegetation restoration in semi-arid Loess Plateau, China. Catena $115,123-133$.

Yang, L., Chen, L.D., Wei, W., 2015. Effects of vegetation restoration on the spatial distribution of soil moisture at the hillslope scale in semi-arid regions. Catena 124, 138-146.

Yin, Z., Cao, J., Li, Z., Qiu, D., 2016. Optimizing the interaction between poly (vinyl alcohol) and sandy soil for enhanced water retention performance. RSC Adv. 6, 13377-13383.

Zhang, W.B., Fu, J.S., 2003. Rainfall erosivity estimation under different rainfall amount. Resour. Sci. 25, 35-41 (in Chinese).

Zhang, X., Zhao, W.W., Liu, Y.X., Fang, X.N., Feng, Q., Chen, Z.F., 2016. Spatial variations and impact factors of soil water content in typical natural and artificial grasslands: a case study in the Loess Plateau of China. J. Soils Sediments 17, 1-15.

Zheng, Z.M., Fu, B.J., Hu, H.T., Sun, G., 2014. A method to identify the variable ecosystem services relationship across time: a case study on Yanhe Basin, China. Landsc. Ecol. 29, 1689-1696.

Zheng, Z.M., Fu, B.J., Feng, X.M., 2016. Gis-based analysis for hotspot identification of tradeoff between ecosystem services: a case study in Yanhe Basin, China. Chin. Geogr. Sci. 26, 466-477. 